\title{
Dynamic Response and Failure Characteristics of Slope with Weak Interlayer under Action of Near-Fault Ground Motion
}

\author{
Bing Yang $\mathbb{D}^{1},{ }^{1}$ Jiangrong Hou $\mathbb{D}^{1},{ }^{1}$ Yifei Liu $\mathbb{D}^{1,2}$ and Zihong Zhou $\mathbb{D}^{1}$ \\ ${ }^{1}$ School of Civil Engineering, Southwest Jiaotong University, Chengdu 610031, China \\ ${ }^{2}$ College of Civil and Transportation Engineering, Shenzhen University, Shenzhen 51800, China
}

Correspondence should be addressed to Yifei Liu; yfliu@szu.edu.cn

Received 3 March 2021; Revised 7 April 2021; Accepted 17 April 2021; Published 3 May 2021

Academic Editor: Chuanbin Zhu

Copyright (c) 2021 Bing Yang et al. This is an open access article distributed under the Creative Commons Attribution License, which permits unrestricted use, distribution, and reproduction in any medium, provided the original work is properly cited.

Investigations into the Wenchuan earthquake (2008, China) demonstrated that landslides were concentrated in the near-fault areas, and numerous large-scale landslides occurred in slopes with weak interlayers. A mathematical model was established based on the shear beam theory, while a numerical model was developed based on the discrete element method which perfectly matched layer boundary theory. Through a theoretical analysis and numerical simulation, the dynamic response and failure modes of the slope with a weak interlayer under the near-fault ground motion were studied. It was found that a combined effect took place between the near-fault ground motion and the weak interlayer, causing the slope near a fault to be destroyed more easily. The coupling between the near-fault ground motion and the weak interlayer leads to a maximum amplification effect of the slope. The existence of a weak interlayer induces nonconforming vibration between the upper and the lower rock masses of the interlayer. The variation in the amplification effect along the slope elevation is related to the ratio of the input seismic period to the natural slope period. Under horizontal ground motion, weak interlayers will be subjected to impacting and shearing action. The failure mode of the slope with a weak interlayer under near-fault ground motion can be expressed as a trailing edge tension crack, as well as weak interlayer impacting and shearing failure.

\section{Introduction}

Post-earthquake surveys have demonstrated that damages are evidently concentrated in the epicentral area, regardless of the engineering structure or geological body. The damage amount and degree generally exhibit a negative correlation with the distance from the fault, with a nonlinear attenuation. At a small distance from the fault (near-fault), the amount of destruction accounts for more than $70 \%$ of the total [1-3]. For example, in the Wenchuan earthquake, $81.2 \%$ of the total landslides occurred within $5 \mathrm{~km}$ from the fault [4]. Several strong earthquakes at the end of the $20^{\text {th }}$ century, such as the 1994 Northbridge earthquake in the United States, 1995 Kobe earthquake in Japan, 1999 Izmit earthquake in Turkey, and 1999 Chi-Chi earthquake in Taiwan, China, have provided a large number of near-fault ground motion records. It has been proven that a certain correlation exists between the near-fault ground motion and the disaster concentration [5]. The analysis of these near- fault ground motion records shows that near-fault ground motions exhibit certain characteristics that are evidently different from those of far-field ground motions [6].

The characteristics of near-fault ground motion can be summarized as the following effects: the rupture directivity, fling step, hanging wall, and vertical effects. Among these, the rupture directivity and fling step effects will induce a long-period and large-amplitude velocity pulse. The generating principle of the rupture directivity and fling step effects are illustrated in Figure 1. Taking a strike-slip fault as an example, when the near-fault site is at the end of the fault along the fracture strike, the energy produced by each rupture will be superimposed. Thus, a velocity pulse will appear, which is produced by the rupture directivity effect, and its direction is perpendicular to the fault strike. The characteristic of the velocity pulse produced by the rupture directivity effect is that the pulse appears at the initial stage of ground motion and is bidirectional [7]. In Burks and Baker's study, the bidirectional pulse generated by the direction 

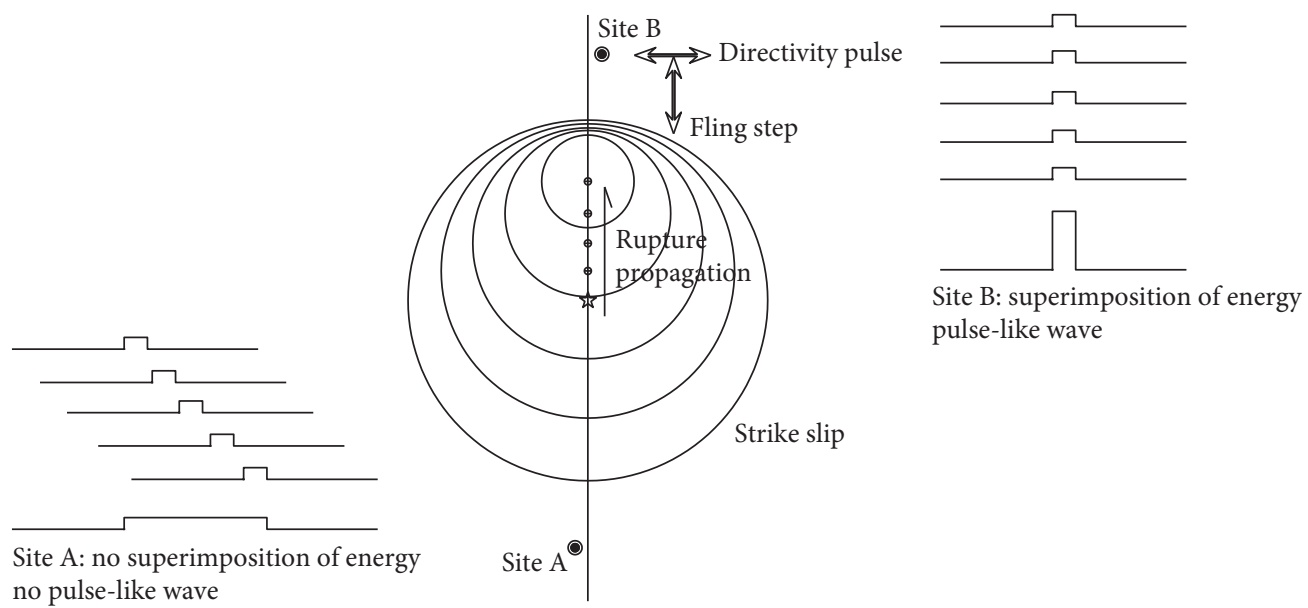

Figure 1: Schematic of causes of fling step and directivity pulse effects.

effect is referred to as the directivity pulse. On the strike parallel to the fault rupture, the dislocation between the two earthquake plates will result in a large permanent displacement of ground. This permanent displacement will induce a long-period, unidirectional large pulse, which is the fling step effect in the near-fault effect [8] (see Figure 1). The unidirectional pulse generated by the fling step effect is referred to as the fling step in this study. Two typical velocity waveforms about the fling step effect and near-fault rupture directivity effect recorded in an earthquake are illustrated in Figure 2, which are the fling step recorded in the 1995 Kobe earthquake (Fukiai) and the directivity pulse recorded in the 1999 Chi-Chi earthquake in Taiwan, China (TCU-068), respectively.

Wen et al. [9] analyzed 64 groups of ground motion records within a distance of $200 \mathrm{~km}$ from the fault in the 2008 Wenchuan earthquake, and they found that seven ground motions within a distance of $30 \mathrm{~km}$ from the fault were pulse-like ground motions. The pulse velocity amplitude measured at Qingping station in Mianzhu county, which is the closest to the fault, was up to $1.26 \mathrm{~m} / \mathrm{s}$. An investigation demonstrated that there were five concentrated areas of large landslides in the Wenchuan earthquake $[9,10]$, as illustrated in Figure 3. If the rupture directivity effect exists, the largest number of landslides should be near the end of the fault, that is, in areas $E$ and $C$. In fact, large landslides do exhibit the greatest distribution in these two areas, accounting for $34.8 \%$ and $28.6 \%$ of the total large-scale landslides, respectively (Figure 4) [2].

As mentioned previously, the two pulse effects mainly affect the parallel and vertical fault directions. Statistical results regarding the direction of large-scale landslides in the Hongshihe basin of Qingchuan county following the Wenchuan earthquake are presented in Figure 5 [2]. From the figure, it can be observed that the sliding directions of the landslides are mainly parallel to and perpendicular to the fault, which further confirms the contribution of the nearfault pulse-like ground motion to the landslides.

The weak interlayer is a layer with a certain thickness, composed of relatively soft materials. In engineering practice, if a weak interlayer exists in the slope, most of the slopes will exhibit stability problems. The weak interlayer is often the controlling factor for the slope instability [11]. Under the action of ground motion, a slope with a weak interlayer will exhibit several different response characteristics compared to a homogeneous slope $[12,13]$. To date, various researchers have studied the seismic response of the slope with a weak interlayer. Huang [14] studied the influence of the elastoplastic parameters of the weak interlayer on the amplification effect by means of the theoretical analysis method. Liu et al. [15] analyzed the influence of a weak interlayer thickness, dip angle, and buried depth on the slope displacement and acceleration using the finite element method. $\mathrm{Xu}$ et al. [16] analyzed the stability of a slope with three largescale weak interlayers using FLAC ${ }^{3 \mathrm{D}}$. Deng et al. [17] studied the failure mode of a slope with a thin sandy layer in the 2004 Niigata Ken Chuetsu earthquake. Huang et al. [18] studied the rotation-translation mechanisms of a slope with a weak interlayer by means of the upper bound stability theory. Chen et al. [11] and Fan et al. [19] studied the seismic response and failure mode of a slope with a weak interlayer using a large-scale shaking table test.

Existing studies on the seismic response of a slope with a weak interlayer have mainly focused on the failure mode, amplification effect, and spectral characteristics of the slope [20]. However, the effect of near-fault ground motion, which exhibits special characteristics, on the weak interlayer has been of less concern, with only few relevant research studies available in the literature.

Near-fault ground motion has many different characteristics from far-field ground motion, and the slope with a weak interlayer also exhibits numerous special dynamic response characteristics compared with the homogeneous slope under the action of ground motion. Postdisaster investigations following the Wenchuan earthquake proved that many of the near-fault landslides triggered by the Wenchuan earthquake contained weak interlayers [2]. For example, in the Daguangbao landslide (at a $4.8 \mathrm{~km}$ distance from the fault), the largest landslide triggered by the Wenchuan earthquake, it was found that the slip zone was the interlayer dislocation zone, and the strength and stiffness of which were smaller than those of 


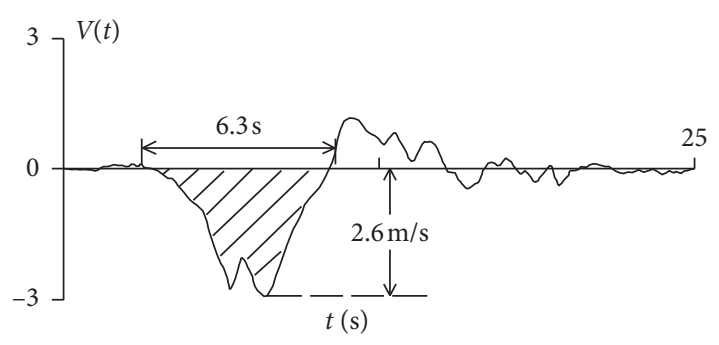

(a)

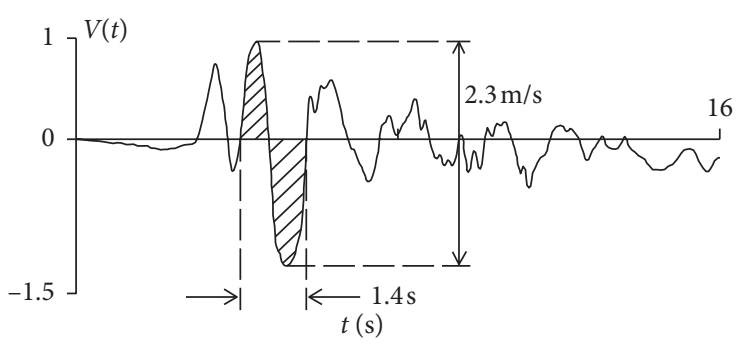

(b)

Figure 2: Typical velocity records of fling step and directivity pulse. (a) Fling step (Kobe earthquake, 1995). (b) Directivity pulse (Chi-Chi earthquake, 1999).

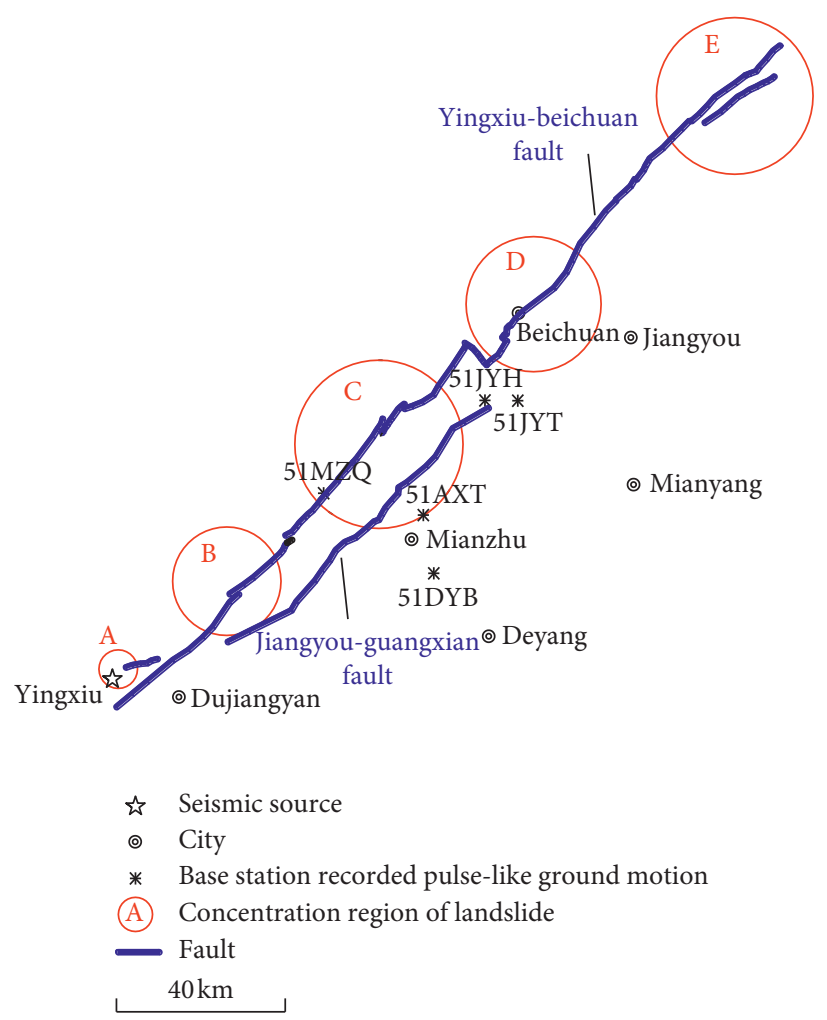

FIGURE 3: Distribution of near-fault pulse-like ground motion records and large-scale landslides in Wenchuan earthquake [9, 10].

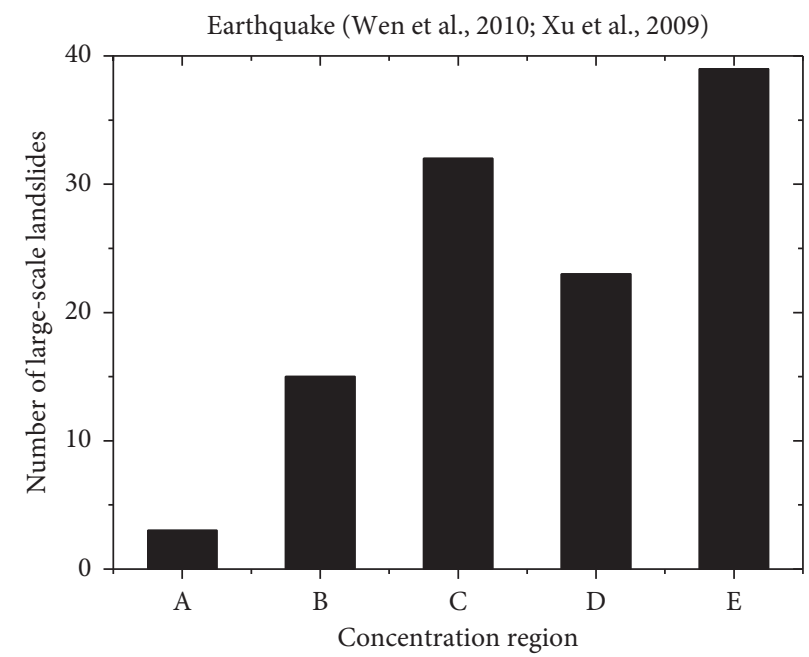

FIGURE 4: Number of large-scale landslides in different concentration regions [2]. 


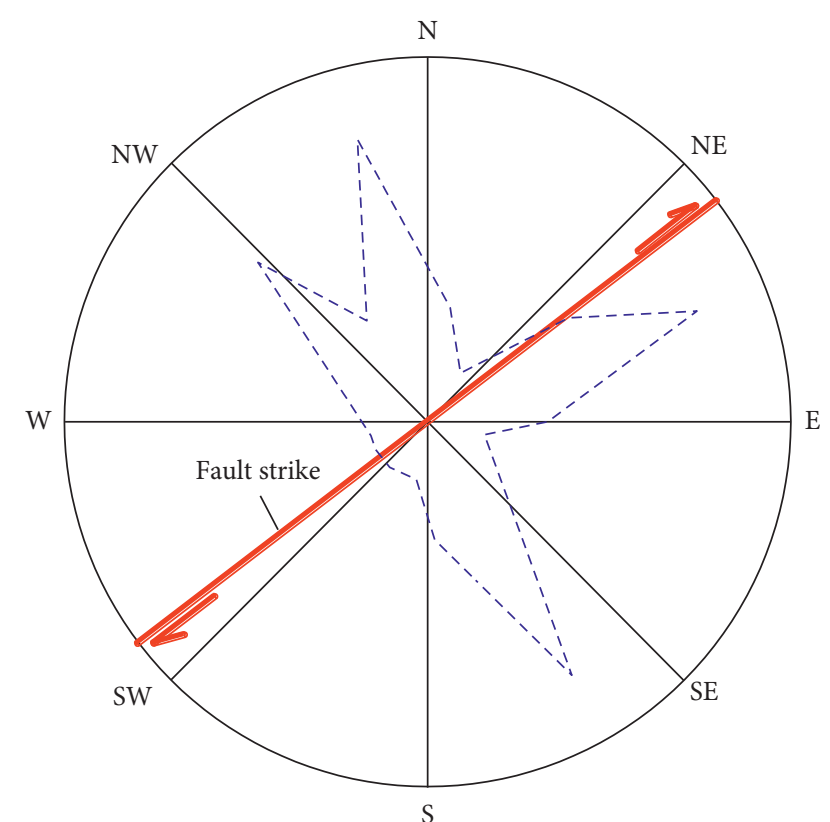

Figure 5: Rosette diagram of sliding directions of large-scale landslides in Hongshihe basin of Qingchuan county [2].

the rock mass at the upper and lower sides of the slip zone [21]. The strength and rigidity of the rock mass in the sliding zone of the Donghekou landslide in the Wenchuan earthquake (at a $300 \mathrm{~m}$ distance from the fault) were also smaller than those of the rock masses above and below the slip zone [22].

When a slope with a weak interlayer is located near the fault, owing to the particularity of the weak interlayer and fault, the question is whether the combination effect of both, which will amplify the slope destruction, will be induced. In this study, this combination effect is investigated. The dynamic response of the slope with a weak interlayer under the action of near-fault pulse-like ground motion is discussed. Moreover, the failure mechanism induced by the combined effect is studied.

\section{Theoretical Analysis}

2.1. Theoretical Model. The dynamic response of a slope with a weak interlayer under the action of horizontal ground motion was considered. Furthermore, a mathematical model for the dynamic response of a slope with a weak interlayer was established.

To develop the model, the following assumptions were made: (1) an infinitely long trapezoidal slope is situated on a rigid foundation, and no relative sliding occurs between the slope and foundation, as indicated in Figure 6. (2) Only the horizontal displacement caused by the earthquake is considered, and the shear stress is uniformly distributed in any horizontal plane. The displacement of each point in the same horizontal plane is the same. (3) The slope is divided into three layers by the weak interlayer (Figure 6), and the physical properties of the materials of each layer are consistent.

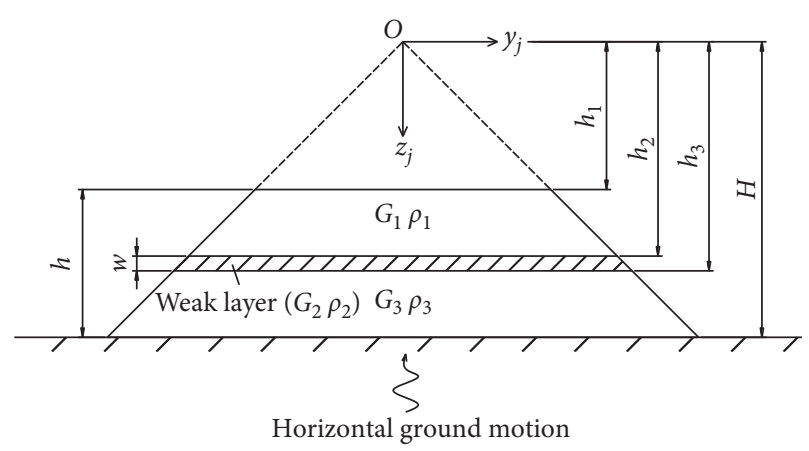

Figure 6: Model diagram.

For any slope, taking a thin layer (the microsegment) from the slope (Figure 7 ), the equilibrium equation in the horizontal direction can be expressed as

$$
\frac{\partial^{2} u_{j}}{\partial t^{2}} \mathrm{dm}_{j}+\tau_{j} b\left(z_{j}\right)=\left(\tau_{j}+\frac{\partial \tau_{j}}{\partial z_{j}}\right)\left(b\left(z_{j}\right)+\frac{\partial b\left(z_{j}\right)}{\partial z_{j}} \mathrm{~d} z_{j}\right)+F\left(z_{j}\right)
$$

where $\mathrm{dm}_{j}$ is the microsegment mass, $t$ is the time, $u_{j}$ is the horizontal displacement, $\tau_{j}$ is the shear stress uniformly distributed in any horizontal section, $b\left(z_{j}\right)$ is the microsegment width, $F\left(z_{j}\right)$ is the horizontal external force acting on the microsection, and the subscript $j=1,2,3$ (1 refers to the layer above the weak layer, 2 refers to the weak layer, and 3 refers to the layer below the weak layer). Moreover, $d m_{j}=\rho_{j} b\left(z_{j}\right) \mathrm{d} z_{j}, b\left(z_{j}\right)=\alpha z_{j}$ (let the slope angle be $\theta$, $\alpha=1 / \tan \theta$; here, $\theta=45^{\circ}$, namely, $\left.\alpha=1\right), \tau_{j}=G_{j}\left(\partial u_{j} / \partial z_{j}\right)$, and $F\left(z_{j}\right)=\left(\mathrm{d}^{2} u_{0} / \mathrm{d} t^{2}\right) \mathrm{dm}_{j}$. Substituting the above parameters into equation (1), the equation of slope vibration under the action of horizontal ground motion can be written as

$$
\frac{\partial u_{j}^{2}}{\partial t^{2}}-\frac{G_{j}}{\rho_{j}}\left(\frac{\partial^{2} u_{j}}{\partial z_{j}^{2}}+\frac{1}{z_{j}} \frac{\partial u_{j}}{\partial z_{j}}\right)=-\frac{\mathrm{d}^{2} u_{0}}{\mathrm{~d} t^{2}}
$$

where $\rho_{j}$ is the density of each layer material and $G_{j}$ is the shear modulus of each layer material.

Let the right-hand side of equation (2) be equal to 0 . Then, a linear homogeneous equation can be obtained, which can be solved by the separation variables' method. Suppose that

$$
u_{j}\left(z_{j}, t\right)=\phi_{j}\left(z_{j}\right) T(t)
$$

Substituting equations (3) into (2), and letting both sides of the equation be equal to $-c_{j}^{2}$,

$$
\begin{array}{r}
\frac{\mathrm{d}^{2} T(t)}{\mathrm{d} t^{2}}+\frac{G_{0} c_{j}^{2} T(t)}{\rho}=0, \\
\frac{\mathrm{d}^{2} \phi_{j}\left(z_{j}\right)}{\mathrm{d} z_{j}^{2}}+\frac{1}{z_{j}} \frac{\mathrm{d} \phi_{j}\left(z_{j}\right)}{\mathrm{d} z_{j}}+c_{j}^{2} \phi_{j}\left(z_{j}\right)=0 .
\end{array}
$$

The general solution of equation (4) is as follows: 


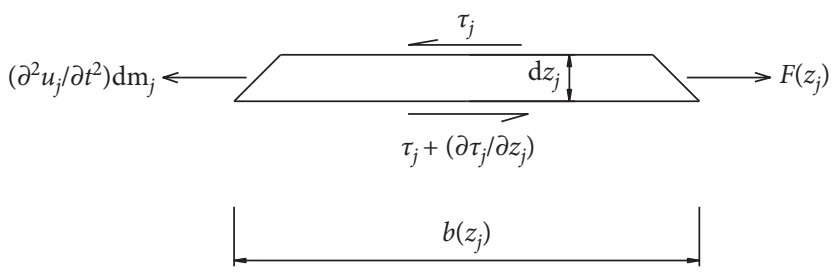

FIGURE 7: Force analysis of the element.

$$
T(t)=T(0) \cos (\omega t)+\frac{T(0)}{\omega} \sin (\omega t),
$$

where $\omega$ is the angular frequency:

$$
\omega=\frac{G_{j} c_{j}^{2}}{\rho_{j}} .
$$

From equation (7), it can be concluded that

$$
c_{j}=\omega \sqrt{\frac{\rho_{j}}{G_{j}}} .
$$

Let $Z_{j}=c_{j} z_{j}$; then, equation (5) can be reduced to a 0 order Bessel equation:

$$
Z_{j}^{2} \frac{\mathrm{d}^{2} \phi\left(Z_{i}\right)}{\mathrm{d} Z_{j}^{2}}+Z_{j} \frac{\mathrm{d} \phi\left(Z_{j}\right)}{\mathrm{d} Z_{j}}+Z_{j}^{2} \phi\left(Z_{j}\right)=0 .
$$

The solution to equation (9) can be expressed by the Bessel function:

$$
\phi\left(Z_{j}\right)=Z_{j}^{0}\left[A_{j} J_{0}\left(Z_{j}\right)+B_{j} Y_{0}\left(Z_{j}\right)\right],
$$

where $J_{0}\left(Z_{j}\right)$ and $Y_{0}\left(Z_{j}\right)$ are the first and second types of 0 order Bessel functions, respectively, while $A_{j}$ and $B_{j}$ are the parameters to be calculated.
The boundary condition of the slope with a weak interlayer (see Figure 6) can be expressed as follows: (1) the shear stress at the top of the slope is 0 ; (2) the shear displacement at the bottom of the slope is 0 ; and, (3) the shear displacement and stress satisfy the continuity condition at the interlayer interface. The mathematical form can be written as

$$
\begin{aligned}
\left.G_{1}\left(z_{1}\right) u_{1}^{\prime}\left(z_{1}\right)\right|_{z_{1}=h_{1}} & =0, \\
\left.G_{1}\left(z_{1}\right) u_{1}^{\prime}\left(z_{1}\right)\right|_{z_{1}=h_{2}}-\left.G_{2}\left(z_{2}\right) u_{2}^{\prime}\left(z_{2}\right)\right|_{z_{2}=h_{2}} & =0, \\
\left.u_{1}\left(z_{1}\right)\right|_{z_{1}=h_{2}}-\left.u_{2}\left(z_{2}\right)\right|_{z_{2}=h_{2}} & =0, \\
\left.G_{2}\left(z_{2}\right) u_{2}^{\prime}\left(z_{2}\right)\right|_{z_{2}=h_{3}}-\left.G_{3}\left(z_{3}\right) u_{3}^{\prime}\left(z_{3}\right)\right|_{z_{3}=h_{3}} & =0, \\
\left.u_{2}\left(z_{2}\right)\right|_{z_{2}=h_{3}}-\left.u_{3}\left(z_{3}\right)\right|_{z_{3}=h_{3}} & =0, \\
\left.G_{3}\left(z_{3}\right) u_{3}^{\prime}\left(z_{3}\right)\right|_{z_{3}=H} & =0 .
\end{aligned}
$$

Substituting equations (10) into (11), the following algebraic equation can be obtained:

$$
E C=0 \text {, }
$$

in which

$$
\begin{aligned}
E & =\left[\begin{array}{cccccc}
G_{1} J_{-1}\left(c_{1} h_{1}\right) & G_{1} Y_{-1}\left(c_{1} h_{1}\right) & 0 & 0 & 0 & 0 \\
G_{1} J_{-1}\left(c_{1} h_{2}\right) & G_{1} Y_{-1}\left(c_{1} h_{2}\right) & -G_{2} J_{-1}\left(c_{2} h_{2}\right) & -G_{2} Y_{-1}\left(c_{2} h_{2}\right) & 0 & 0 \\
J_{0}\left(c_{1} h_{2}\right) & Y_{0}\left(c_{1} h_{2}\right) & -J_{0}\left(c_{2} h_{2}\right) & -Y_{0}\left(c_{2} h_{2}\right) & 0 & 0 \\
0 & 0 & G_{2} J_{-1}\left(c_{2} h_{3}\right) & G_{2} Y_{-1}\left(c_{2} h_{3}\right) & -G_{3} J_{-1}\left(c_{3} h_{3}\right) & -G_{3} Y_{-1}\left(c_{3} h_{3}\right) \\
0 & 0 & J_{0}\left(c_{2} h_{3}\right) & Y_{0}\left(c_{2} h_{3}\right) & -J_{0}\left(c_{3} h_{3}\right) & -Y_{0}\left(c_{3} h_{3}\right) \\
0 & 0 & 0 & 0 & J_{0}\left(c_{3} H\right) & Y_{0}\left(c_{3} H\right)
\end{array}\right], \\
C & =\left[\begin{array}{l}
A_{1} \\
B_{1} \\
A_{2} \\
B_{2} \\
A_{3} \\
B_{3}
\end{array}\right] .
\end{aligned}
$$


If equation (12) has a nonzero solution, it is necessary to let the coefficient determinant of the equation be equal to 0 , and then,

$$
|E|=0
$$

The natural frequencies $\omega_{i}(i=1,2,3, \ldots)$ of the slope can be obtained by solving equation (14). Let $A_{1}=1$, and the values of $B_{1}, A_{2}, B_{2}, A_{3}$, and $B_{3}$, represented by $A_{1}$, can be obtained according to equation (12). Thus, the main vibration modes of each order can be written as

$$
\varphi_{i}(z)= \begin{cases}Z_{1}^{0}\left[A_{1} J_{0}\left(Z_{1}\right)+B_{1} Y_{0}\left(Z_{1}\right)\right], & \left(Z_{1}=\omega_{i} \sqrt{\frac{\rho_{1}}{G_{1}}} z, h_{1} \leq z<h_{2}\right), \\ Z_{2}^{0}\left[A_{2} J_{0}\left(Z_{2}\right)+B_{2} Y_{0}\left(Z_{2}\right)\right], & \left(Z_{2}=\omega_{i} \sqrt{\frac{\rho_{2}}{G_{2}}} z, h_{2} \leq z<h_{3}\right), \\ Z_{3}^{0}\left[A_{3} J_{0}\left(Z_{3}\right)+B_{3} Y_{0}\left(Z_{3}\right)\right], & \left(Z_{3}=\omega_{i} \sqrt{\frac{\rho_{3}}{G_{3}}} z, h_{3} \leq z \leq H\right) .\end{cases}
$$

The main vibration mode corresponding to each order frequency has thus been obtained, and the vibration equations corresponding to each order frequency under the action of ground motion can be determined by the mode decomposition method.

Define the $i^{\text {th }}$-order generalized mass as

$$
m_{i}=\sum_{j=1}^{3} \int_{h_{j}^{-}}^{h_{j}^{+}} \rho_{j}(\alpha z)\left[\varphi_{i}(z)\right]^{2} \mathrm{~d} z .
$$

The generalized load of the $i^{\text {th }}$ order is

$$
P_{i}(t)=-\frac{\mathrm{d} u_{0}^{2}}{\mathrm{~d} t^{2}} \sum_{j=1}^{3} \int_{h_{j}^{-}}^{h_{j}^{+}} \alpha z \rho_{j}\left[\varphi_{i}(z)\right]^{2} \mathrm{~d} z .
$$

For each vibration mode, the vibration equations can be expressed as

$$
m_{i} \frac{\mathrm{d} Y_{i}^{2}(t)}{\mathrm{d} t^{2}}+\omega_{i}^{2} m_{i} Y_{i}(t)=P_{i}(t) .
$$

The vibration function can be obtained by applying the Duhamel integral:

$$
u(z, t)=\sum_{i=1}^{\infty} \frac{1}{m_{i} \omega_{i}} \varphi_{i}(z) \int_{0}^{t} P_{i}(s) \sin \left[\omega_{i}(t-s)\right] \mathrm{d} s,
$$

where $s$ is the integral time of the Duhamel integral, and $0 \leq s \leq t$.

\subsection{Characteristics of Natural Frequency and Vibration Mode} of the Slope with the Weak Interlayer. Considering a trapezoidal slope with a height of $30 \mathrm{~m}$ (Figure 6), the slope is homogeneous and has no interlayer. The shear modulus of the rock mass is set to $G_{1}=G_{2}=G_{3}=200 \mathrm{MPa}$, and the density is assumed to be $2650 \mathrm{~kg} / \mathrm{m}^{3}$. According to the frequency equation (equation (14)), the first-order natural frequency of the homogeneous slope is calculated as $2.62 \mathrm{~Hz}$. When a weak interlayer exists in the middle of the slope, the thickness of the soft interlayer is set to $4 \mathrm{~m}$, and the shear modulus of the rock mass is assumed to be $G_{2}=G_{1}$ / $4=50 \mathrm{MPa}$ (Figure 6). According to the frequency equation, the first-order natural frequency of the slope with a weak interlayer is $1.87 \mathrm{~Hz}$. It can be observed that the existence of a weak interlayer evidently reduces the first natural frequency of the slope. This means that a slope with a weak interlayer has a longer period (lower frequency) compared to that of a homogeneous slope. In the example above, the period of the slope with a weak interlayer is 1.44 times longer than that of the homogeneous slope.

Suppose that the shear modulus of the rock mass above and below the weak interlayer $G_{1}=G_{3}=200 \mathrm{MPa}$, and the shear modulus of the weak interlayer material is $G_{2}$. The weak interlayer thickness is assumed to be $w$, and the weak interlayer is located in the middle of the slope. With the variation in the shear modulus and thickness of the weak interlayer, the ratio of the first-order natural period $(T)$ of the slope with a weak interlayer to the first-order natural period $\left(T_{0}\right)$ of the homogeneous slope is illustrated in Figure 8 . It can be observed from the figure that the period ratio $T / T_{0}$ increases with an increase in $G_{1} / G_{2}$ and $w / h$.

As mentioned previously, the near-fault ground motion has a longer period and larger pulse, which will lead to greater damage to long-period structures [23]. The existence of the weak interlayer causes the first-order natural period of the slope to be longer. Therefore, the existence of a weak interlayer coupled with near-fault ground motion will cause greater damage.

The formula provided by Bray [24] is used to estimate natural period of nine large-scale landslides within a $5 \mathrm{~km}$ distance from the fault in the Wenchuan earthquake, in which the nine large-scale landslides are regarded as a homogeneous slope. The estimation formula is presented in equation (20), and the estimated results are displayed in Table 1 as follows:

$$
T_{s}=4 \frac{H_{m}}{v_{s}}
$$

where $T_{s}$ is the estimated natural period of the slope regarded as a homogeneous mass, $v_{s}$ is the shear wave velocity, and $H_{m}$ is the slope height.

The period $T_{i}=6.52 \mathrm{~s}$, that is, the minimum pulse period of the pulse-like ground motion measured in the Wenchuan earthquake [10] is taken as the dynamic input, and the distribution of the period ratio $\left(T_{\mathrm{i}} / T_{\mathrm{s}}\right)$ for the above nine large landslides is illustrated in Figure 9. As can be observed from Figure 9, the pulse period of the Wenchuan earthquake is approximately 1.5 to 2.5 times the natural period of the slope regarded as a homogeneous mass. However, Figure 8 demonstrates that the existence of the weak interlayer increases the natural period of the slope. Compared to the homogeneous slope, the natural period of the slope with a weak interlayer is closer to the pulse period of the near-fault ground motion, so it will cause greater damage.

According to equation (15), the displacement diagram of the first four vibration modes for different shear modulus ratios is presented in Figure 10, when the weak interlayer is in the middle of the slope and $w / h=0.13$. It can be observed from the vibration mode diagram that the vibration 


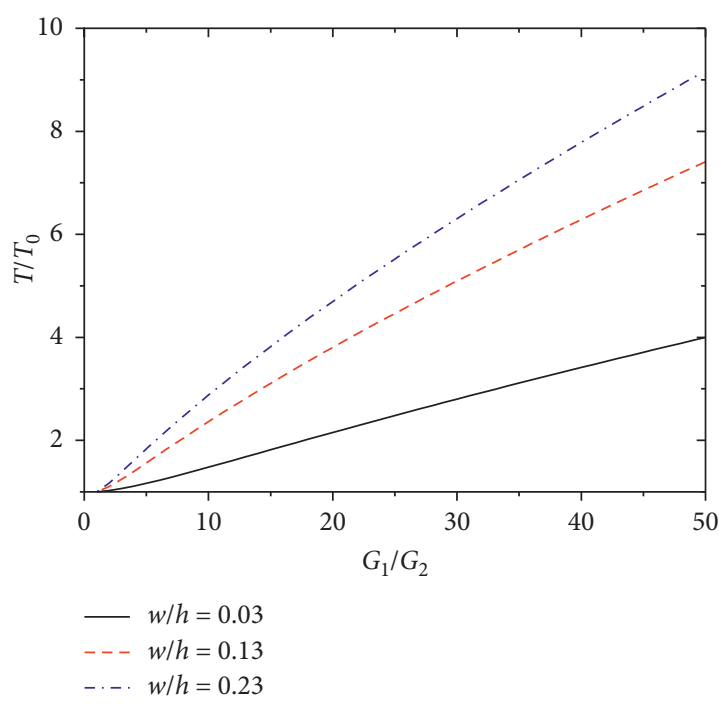

(a)

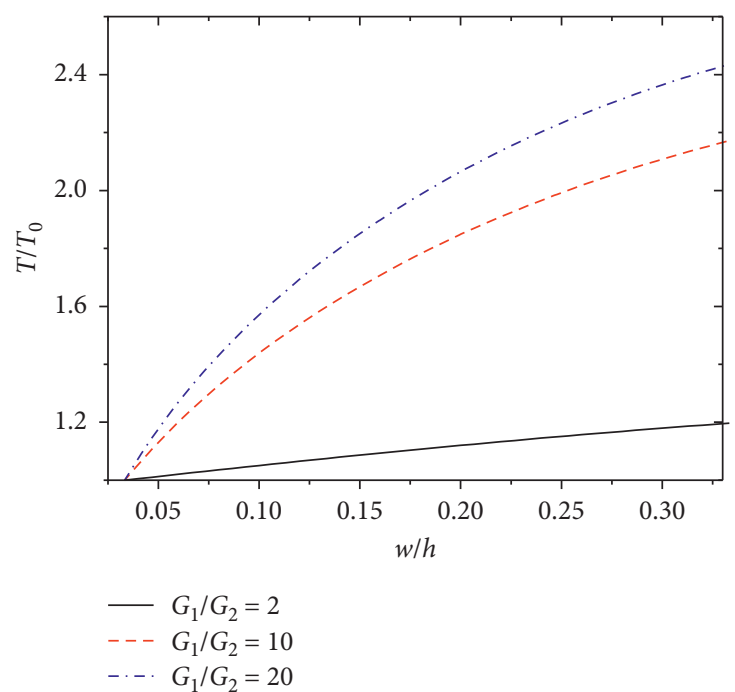

(b)

Figure 8: Variation in the period ratio $T / T_{0}$ with shear modulus and thickness. (a) Shear modulus ratio. (b) Thickness ratio.

TABLE 1: Estimated natural period of large-scale landslides in Wenchuan earthquake.

\begin{tabular}{lcccc}
\hline Name & Distance from fault $(\mathrm{km})$ & Slope height $(\mathrm{m})$ & Shear wave velocity $(\mathrm{m} / \mathrm{s})$ & Estimated period $(\mathrm{s})$ \\
\hline Daguang Bao landslide & 4.8 & 1800 & 1200 & 3.9 \\
Guantan landslide & 0.5 & 700 & 800 & 1000 \\
Eagle Rock landslide & 1.1 & 900 & 1200 & 3.5 \\
Tangjiashan landslide & 2.8 & 800 & 800 & 2.6 \\
Wang Jiayan landslide & 0.4 & 400 & 1200 & 2.7 \\
Donghekou landslide & 0.3 & 800 & 1200 & 2.7 \\
Wo qian landslide & 0.2 & 600 & 1000 & 1.2 \\
Shibangou landslide & 2.4 & 300 & 1000 & 2.4 \\
Wenjiagou landslide & 3.9 & 600 & & \\
\hline
\end{tabular}

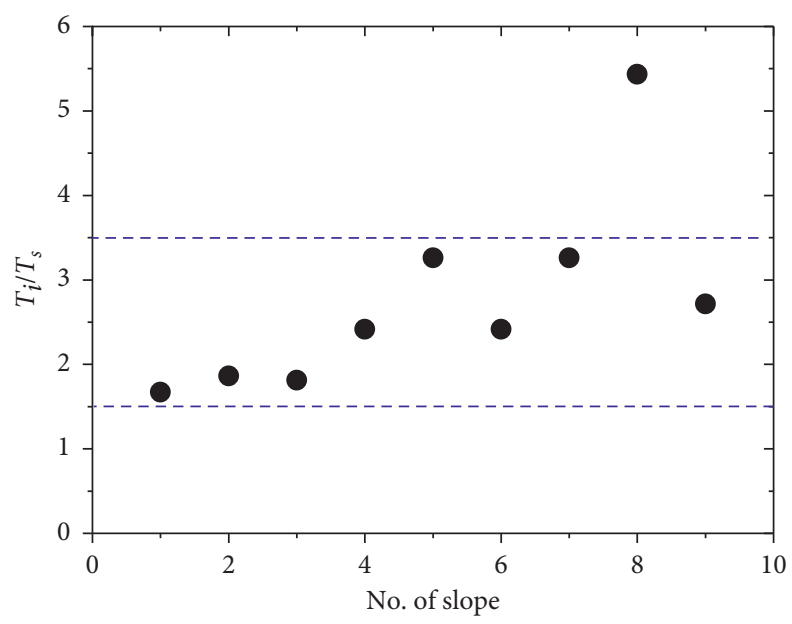

FIGURE 9: Ratio of the pulse-like ground motion period to the natural period of the large-scale landslide regarded as a homogeneous mass in Wenchuan earthquake.

displacement has an inflection point at the intersection of the layers, and the shear strain is discontinuous at this point. Moreover, the first two-order vibration modes vary in nearly the same manner along the slope elevation. From the third mode, the vibration mode along the slope elevation varies significantly between the different shear modulus ratios (Figures $10(\mathrm{c})$ and $10(\mathrm{~d})$ ). The first vibration mode makes the greatest contribution to the final dynamic response. The figure indicates that a smaller shear modulus of the interlayer (that is, a higher ratio of $G_{1} / G_{2}$ ) results in a greater 


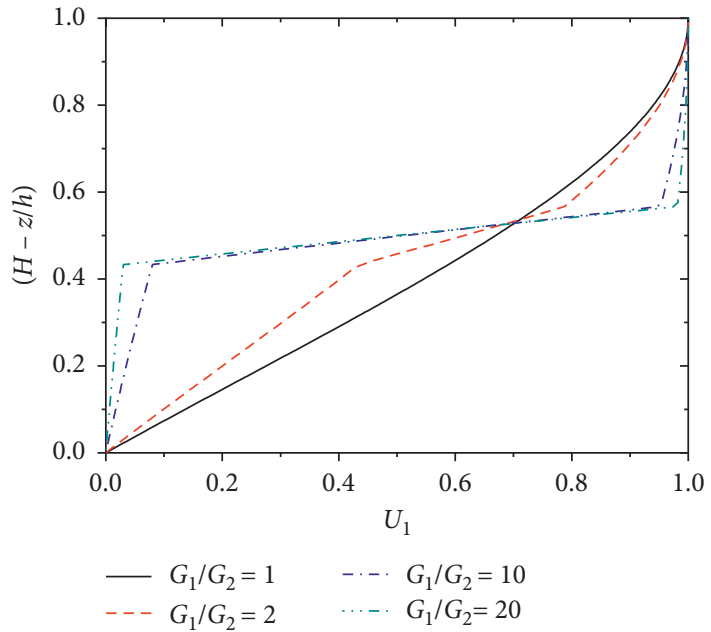

(a)

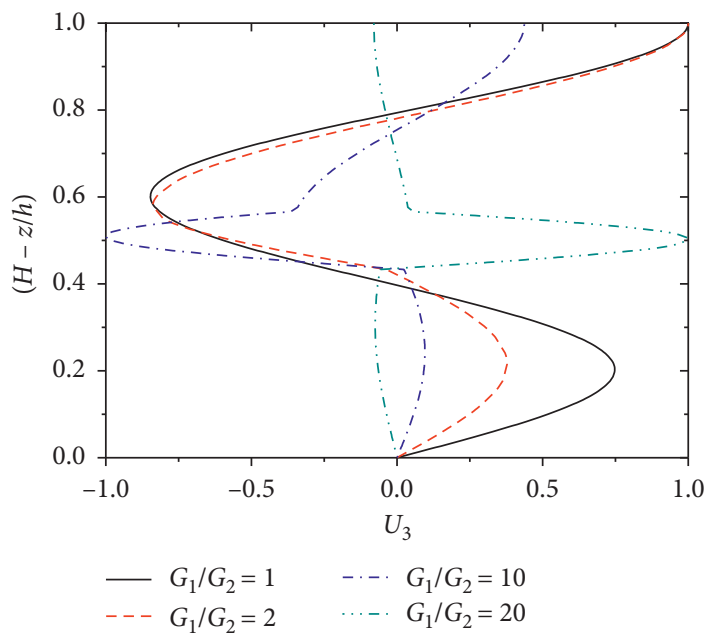

(c)

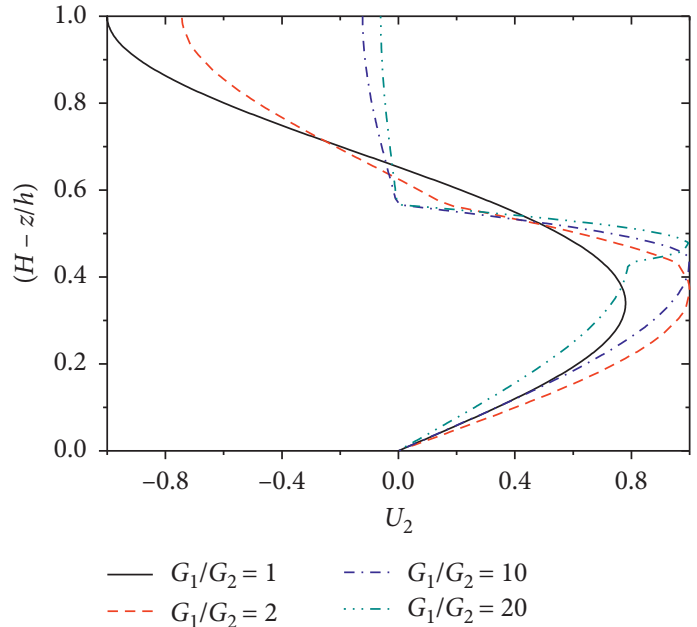

(b)

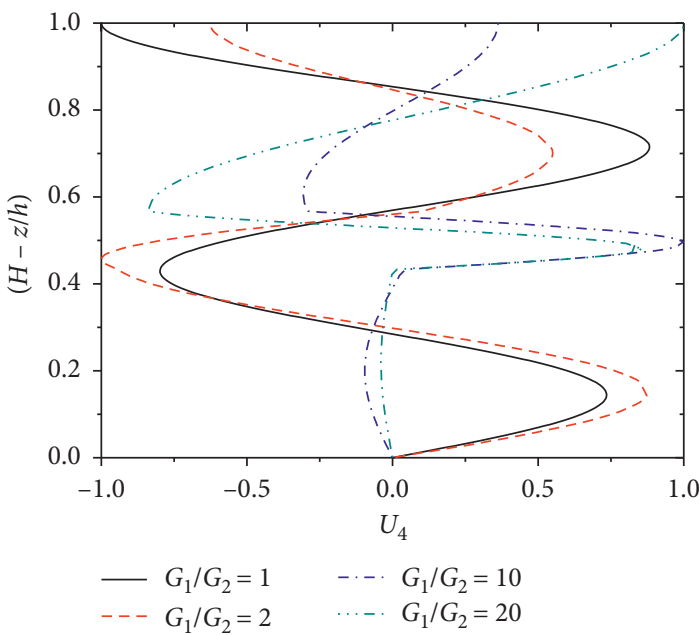

(d)

Figure 10: Displacement functions of first four vibration modes under different natural periods. (a) First vibration mode. (b) Second vibration mode. (c) Third vibration mode. (d) Fourth vibration mode.

difference between the displacements of the rock mass above and below the interlayer. This delamination phenomenon will lead to evidently nonconforming vibration, which will amplify the damage degree.

\subsection{Dynamic Response of the Slope with the Weak Interlayer.} The homogeneous model and weak interlayer slope model described in Section 2.2 are taken as an example. A sine wave is selected to simulate the seismic waves, which offers the advantages of single frequency and uniform amplitude. Therefore, certain laws may be investigated more easily. A low-frequency horizontal sinusoidal vibration with a frequency of $2 \mathrm{~Hz}$ and an amplitude of $1 \mathrm{~m} / \mathrm{s}^{2}$ and a highfrequency horizontal sinusoidal vibration with a frequency of $10 \mathrm{~Hz}$ and an amplitude of $1 \mathrm{~m} / \mathrm{s}^{2}$ are exerted at the bottom of the slope. Equation (19) is used to calculate the dynamic response of the slope. The calculated maximum relative displacement (relative to the slope bottom), maximum relative velocity (relative to the slope bottom), and maximum absolute acceleration along the slope elevation are illustrated in Figure 11.

It can be observed from Figure 11 that the displacement, velocity, and acceleration responses of the slope with or without a weak interlayer are close to the first-order vibration mode at a low-frequency input and second-order vibration mode at a high-frequency input. This indicates that the dynamic response of the slope along the slope elevation is mainly related to the input ground motion frequency and natural frequency of the slope. When the frequency of the ground motion is low and therefore closer to the first-order natural frequency of the slope, the slope vibration is close to its first-order vibration mode. The amplification factor exhibits an increasing trend from the bottom to the top. Moreover, it can be observed from Figure 11 that the amplification effect of the two slopes (with and without an interlayer) does not differ significantly at a high frequency, but the amplification effect of the slope with an interlayer is much greater than that of the homogeneous slope at a low frequency. 


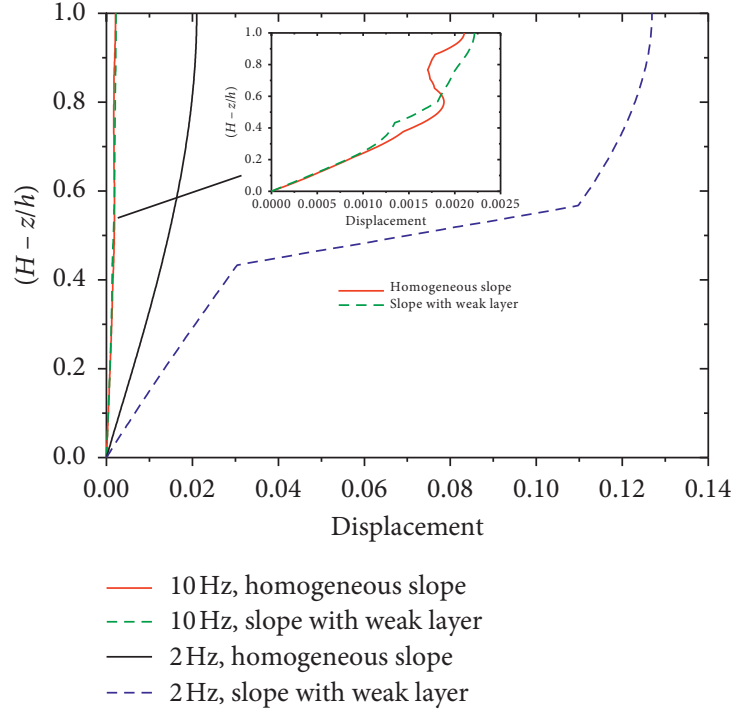

(a)

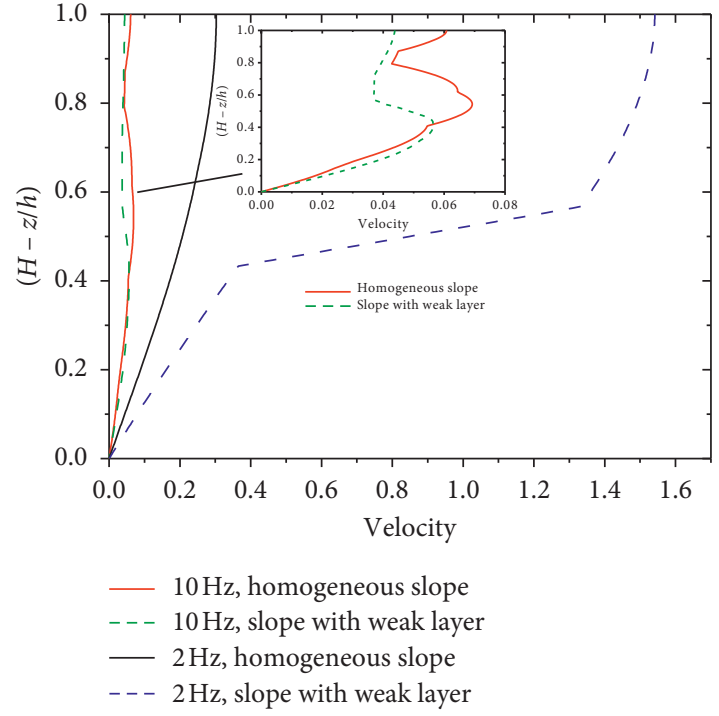

(b)

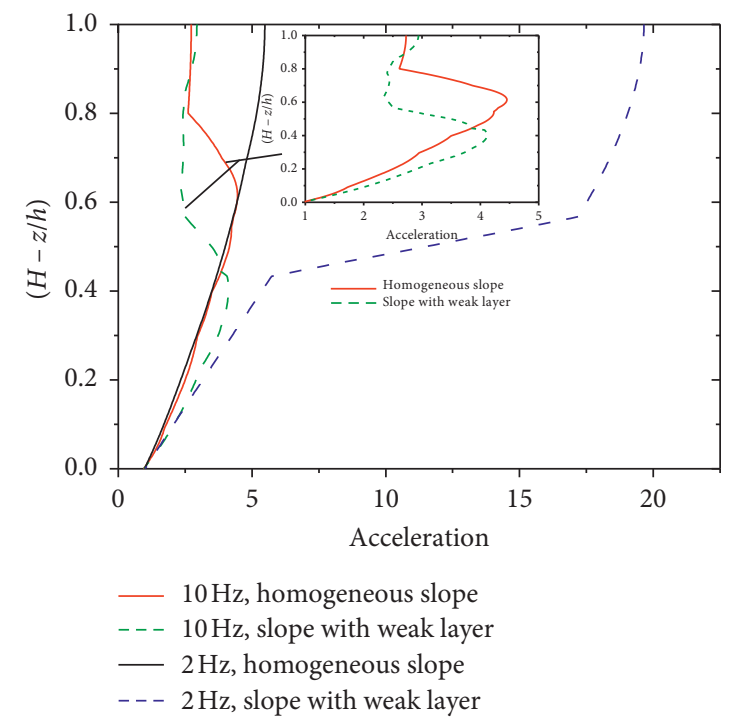

(c)

Figure 11: Dynamic responses at low and high frequencies. (a) Displacement. (b) Velocity. (c) Acceleration.

The pulse-like ground motion is characterized by a long period and low frequency. The maximum relative velocity along the elevation of the homogeneous slope and the slope with a weak interlayer under pulse-like and pulseless ground motions (the waveforms of the two-ground motion are indicated in Figure 12) calculated by equation (19) are illustrated in Figure 13. It can be observed that the results of the pulse-like ground motion are consistent with those of the low-frequency simple harmonic vibration, while the results of the pulseless ground motion are similar to those of the high-frequency simple harmonic vibration. Therefore, the conclusions obtained from the simple harmonic vibration can be also applied to the analysis of pulse-like ground motion.

As the near-fault pulse-like ground motion is a low-frequency ground motion, the coupling between the pulse-like ground motion and weak interlayer will lead to a greater elevation amplification effect. It can also be observed from
Figures 11 and 13 that a significant velocity difference exists between the upper and lower rock masses of the weak interlayer. This means that a distinct incompatible vibration occurs between the rock masses above and below the interlayer. Figure 14 presents the velocity time history of the measuring points above and below the interlayer under the condition of low-frequency simple harmonic vibration. For a homogeneous slope, the velocity difference between the two measuring points is not evident; however, a significant difference exists for the slope with a weak interlayer. In the vibration process, the velocity difference between the rock masses at the top and bottom of the interlayer will cause the weak interlayer to be subjected to impacting and shearing action, resulting in the weak interlayer being damaged more easily.

The amplification effect of the slope and the impacting and shearing effects caused by the velocity difference between the rock masses at the top and bottom of the weak 


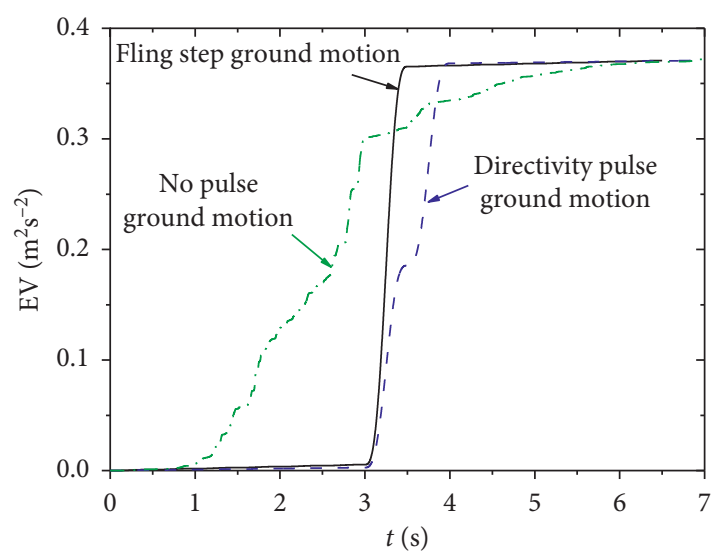

FIGURE 12: Variation in generalized energy with time.

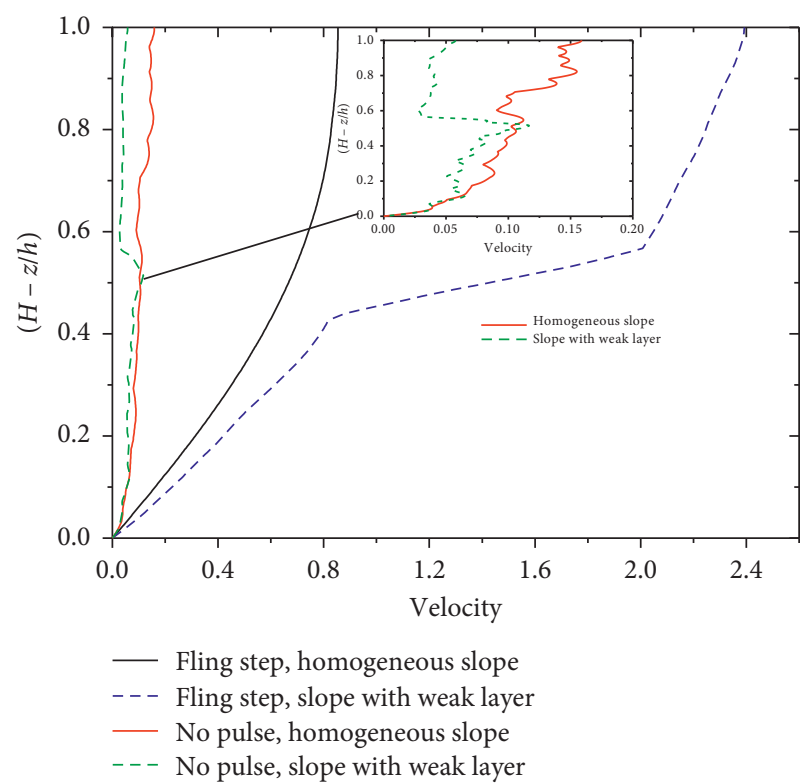

FIGURE 13: Comparison of analytical solutions of pulse-like and pulseless ground motions.

interlayer may be the main reasons for the failure of the weak interlayer. In this study, the peak ground acceleration (PGA) amplification factor at the top of the slope and maximum velocity difference between the rock masses at the top and bottom of the interlayer are used to investigate the two effects. The variations in the PGA and velocity difference with the weak interlayer thickness, shear modulus, and position are presented in Figures 15 and 16.

In Figure 15, the interlayer is in the middle of the slope, and the interlayer thickness and shear modulus are changed. It should be noted that $T_{p}$ is the period of input ground motion, while $T_{s}$ is the natural period of the slope. It can be observed from Figure 15 that the effects of the interlayer thickness and shear modulus on both the PGA amplification factor and maximum velocity difference are realized by changing the first-order natural period of the slope. When the period of the input vibration is the same as the natural period of the slope $\left(T_{p} / T_{s}=1\right)$, the PGA amplification factor and maximum velocity difference are the greatest. A larger

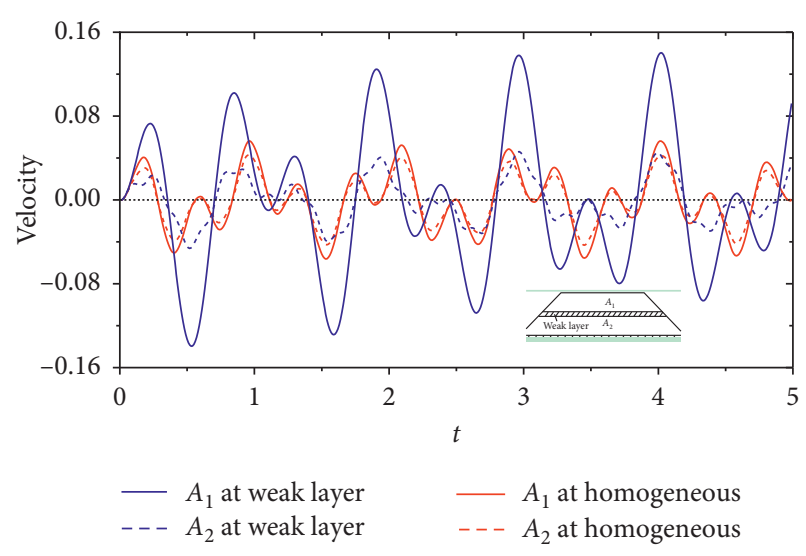

FIGURE 14: Velocity time history of measuring points above and below the interlayer.

difference between the two periods results in a smaller PGA amplification factor and maximum velocity difference. Figure 9 illustrates that the existence of the weak interlayer causes the natural period of the slope to be close to the period of ground motion in the Wenchuan earthquake, which indicates that the ratio $\left(T_{p} / T_{s}\right)$ becomes close to 1 more easily owing to the existence of the weak interlayer in the slope damaged by the Wenchuan earthquake. Therefore, greater damage is caused for the large-scale landslides with a weak interlayer in the Wenchuan earthquake.

Figure 16 illustrates the variations in the PGA amplification factor and maximum velocity difference with the change in $T_{p} / T_{s}$ when the weak interlayer is located at different positions of the slope. It can be observed from the figure that the PGA amplification factor is mainly related to the ratio of the input vibration period to the natural period. For the maximum velocity difference, in addition to the period ratio, the interlayer position has little effect. When the period ratio is the same, the maximum velocity difference is greatest when the interlayer is at the upper part of the slope.

\section{Numerical Simulation}

To provide further understanding of the failure characteristics of the slope with a weak interlayer under near-fault ground motion, it is necessary to establish a numerical model for numerical analysis.

3.1. Discrete Element Method Model of the Slope with the Weak Layer. The discrete element method (DEM) was proposed by Cundall and Strack [25]. Compared to the traditional finite element method, the DEM exhibits no deformation coordination problems and can simulate large deformation, rupture, and inversion of rock and soil.

In this study, a computational model was generated using the software PFC ${ }^{2 \mathrm{D}}$. The contact bond model was used to simulate the adhesion between particles. The height of the slope was set to $40 \mathrm{~m}$, and the angle was set to $45^{\circ}$ (Figure 17). The macroparameters of the slope were set as follows: shear modulus $G_{1}=80 \mathrm{MPa}$, Poisson's ratio $\nu=0.3$, density 

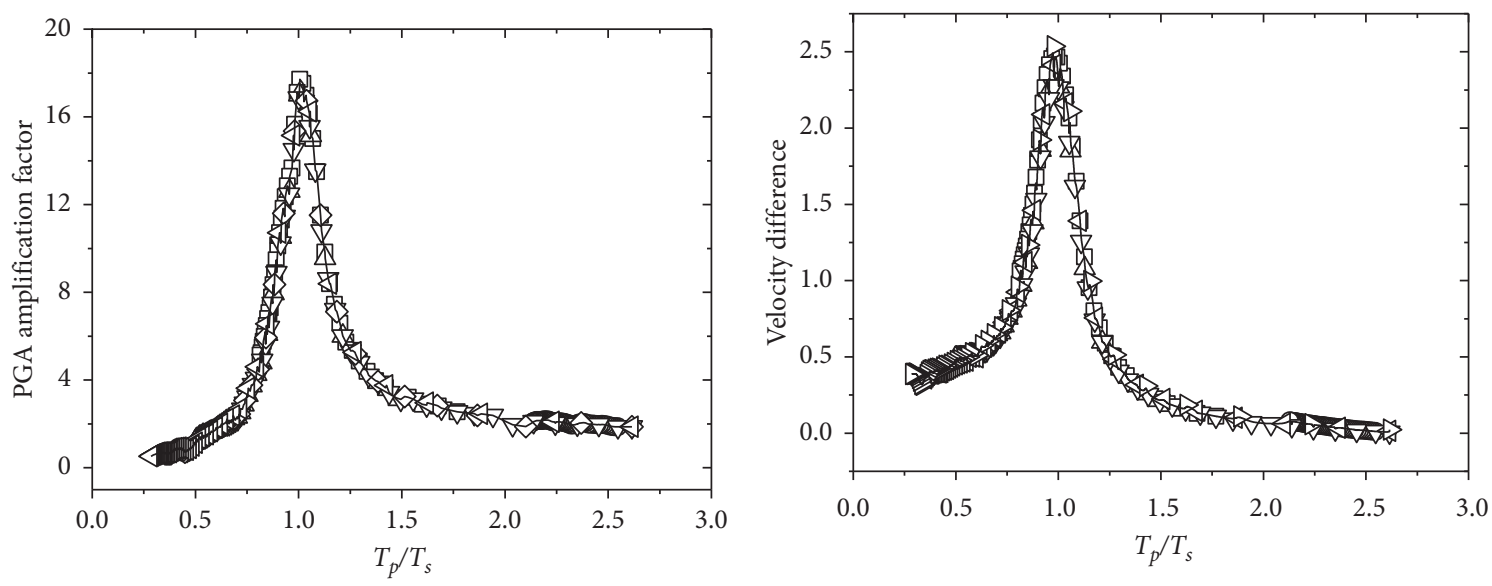

$$
\begin{aligned}
& \square G_{1} / G_{2}=2 \text {, change } w / h \\
& \bigcirc G_{1} / G_{2}=10 \text {, change } w / h \\
& \triangle G_{1} / G_{2}=20 \text {, change } w / h \\
& \nabla w / h=0.03 \text {, change } G_{1} / G_{2} \\
& \diamond w / h=0.13 \text {, change } G_{1} / G_{2} \\
& \triangleleft w / h=0.23 \text {, change } G_{1} / G_{2} \\
& \square \quad \text { Spline }
\end{aligned}
$$

(a) $\square G_{1} / G_{2}=2$, change $w / h$

$\bigcirc G_{1} / G_{2}=10$, change $w / h$

$\triangle G_{1} / G_{2}=20$, change $w / h$

$\nabla w / h=0.03$, change $G_{1} / G_{2}$

$\triangleleft w / h=0.13$, change $G_{1} / G_{2}$

$\triangleright w / h=0.23$, change $G_{1} / G_{2}$

- Spline

(b)

FIGURe 15: Relationship between dynamic response and $T_{p} / T_{s}$. (a) PGA amplification factor at the top of the slope. (b) Maximum velocity difference between the top and bottom of the interlayer.

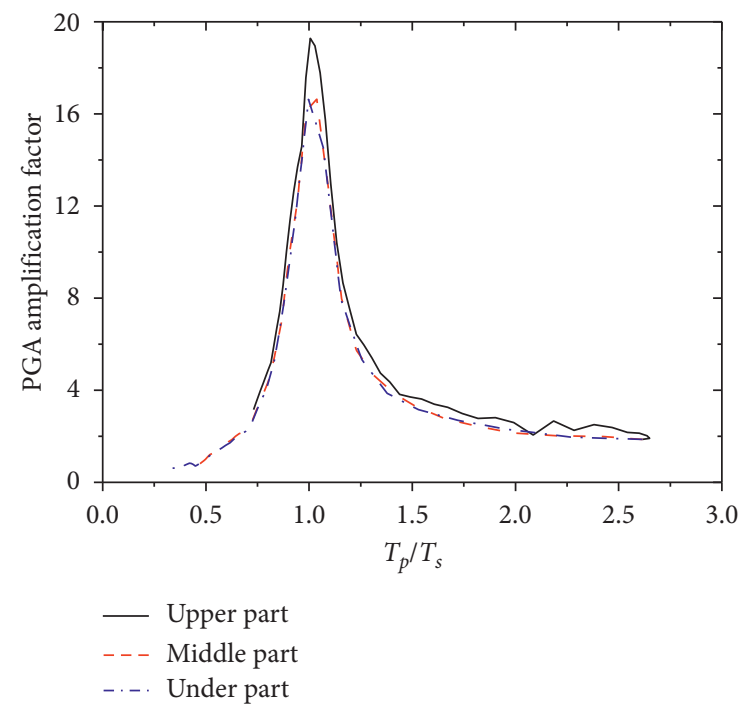

(a)

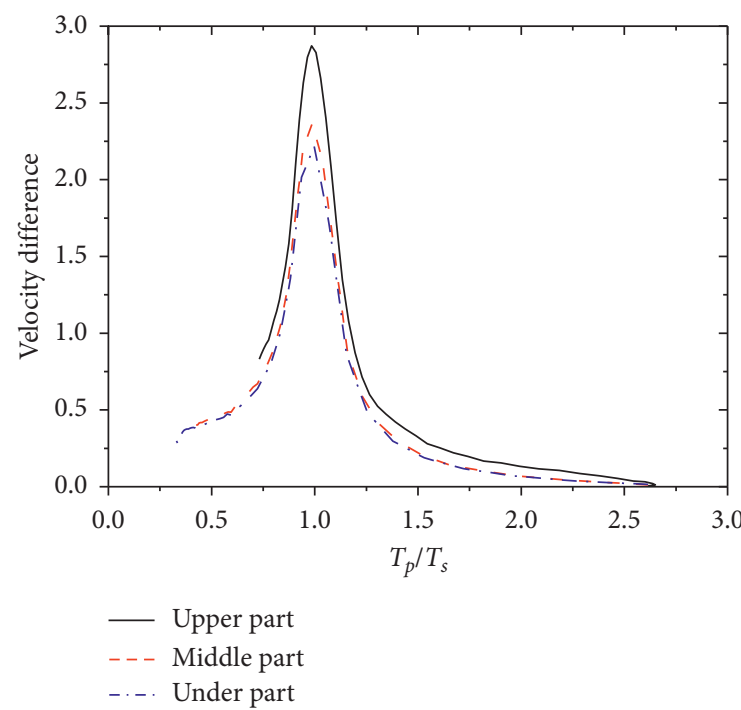

(b)

FIgURE 16: Influence of the interlayer position in the slope on the PGA amplification factor and maximum velocity difference.

$\rho=2650 \mathrm{~kg} / \mathrm{m}^{3}$, cohesion of the rock mass $c=500 \mathrm{kPa}$, and internal friction angle $\phi=30^{\circ}$. According to the static biaxial test, the mesoscopic parameters obtained, corresponding to the macroscopic parameters, are presented in Table 2.

A weak interlayer was set in the middle and lower parts of the slope $(z / h=3 / 8)$. The weak interlayer thickness was $3 \mathrm{~m}$ (Figure 17), and the shear modulus was taken as $1 / 10$ of that of the rock masses above and below the interlayer. The strength was taken as 1/5 of that of the rock mass. The other parameters were the same as those of the rock mass. The corresponding mesoscopic parameters of the weak interlayer are presented in Table 2.

According to the research by $\mathrm{He}$ et al. [26], local damping can better model the energy consumption, and it was therefore used in this study. The damping coefficient was 0.157 . For the pulse-like ground motion, the damping coefficient had little effect on the results. Several calculations show that when the local damping coefficient was not very large, the calculation results for the different local damping coefficients were basically the same. 


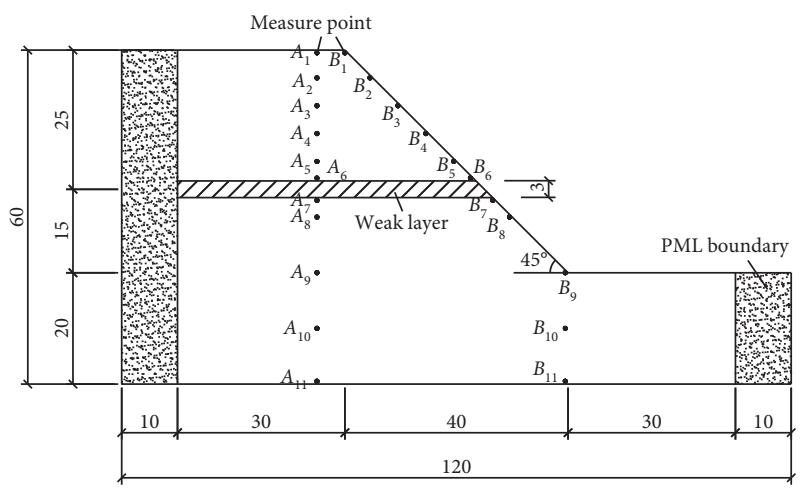

(a)

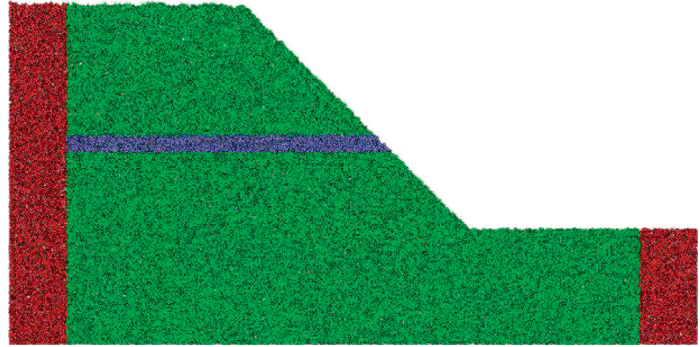

(b)

FIGURE 17: Schematic of the calculation model and PFC2D model.

TABle 2: Mesoscopic parameters of the DEM model.

\begin{tabular}{lcc}
\hline Symbol & Specific description & Value (rock mass/interlayer) \\
\hline$\rho$ & Density $\left(\mathrm{kg} / \mathrm{m}^{3}\right)$ & $2650 / 2650$ \\
$n_{0}$ & Initial porosity & $0.18 / 0.18$ \\
$k_{n}$ & Normal contact stiffness $(\mathrm{Pa})$ & $45 \times 10^{7} / 45 \times 10^{6}$ \\
$k_{s}$ & Tangential contact stiffness $(\mathrm{Pa})$ & $15 \times 10^{7} / 15 \times 10^{6}$ \\
$\sigma_{c}$ & Contact bond normal strength $(\mathrm{Pa})$ & $5.0 \times 10^{5} / 1.0 \times 10^{4}$ \\
$\tau_{c}$ & Contact bond tangential strength $(\mathrm{Pa})$ & $5.0 \times 10^{5} / 1.0 \times 10^{4}$ \\
$f_{c}$ & Friction coefficient & $0.8 / 0.8$ \\
\hline
\end{tabular}

3.2. Boundary Condition. In dynamic problems, the boundary condition has a significant influence on the dynamic analysis results [27] owing to the presence of reflected waves.

The absorbing layer boundary was applied in this study. The boundary of the absorbing layer absorbs the transmission wave by applying an energy-consuming buffer zone outside the calculation area, which is also known as the damping layer. At present, the most representative absorbing boundary is the perfectly matched layer (PML) absorbing boundary. The PML boundary can cause the incident wave to attenuate exponentially, and the false reflection on the boundary can rapidly be attenuated to zero.

In this study, the absorbing effect of the PML was verified by simulating the propagation process of the longitudinal wave in a one-dimensional rock column. As illustrated in Figure 18, a sine wave was applied at the left end, while a PML boundary was set at the right end. The computational results at the measuring point in Figure 19 are illustrated in Figure 18. It can be observed from the figure that the amplitude of the reflection wave was less than $10 \%$ of that of the original incident wave, which indicates that the boundary absorption effect was strong. In this study, the damping absorption layer of the PML boundary set as the slope model boundary is illustrated in Figure 17.

3.3. Ground Motion Input. To judge whether the ground motion is a pulse-like ground motion, Mukhopadhyay and Gupta [28] proposed a method using the ratio of the half-cycle pulse energy to the total ground motion energy to identify the pulse records. The formula for calculating the maximum half-

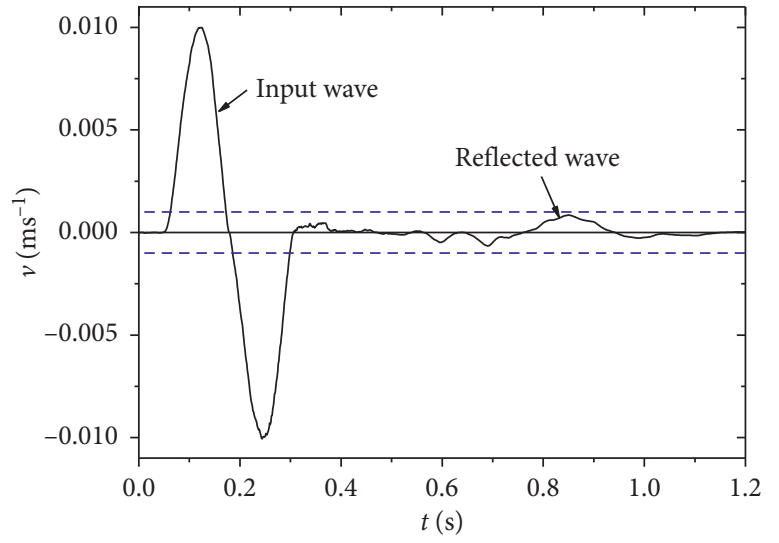

FIGURE 18: Absorption effect of the boundary.

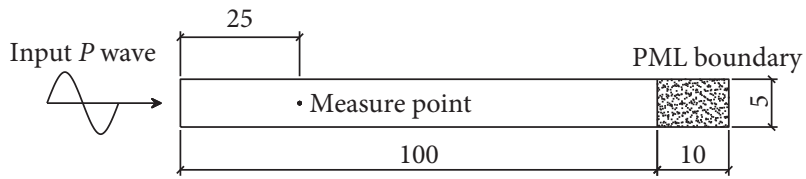

FIgURE 19: Test model of the boundary.

cycle energy ratio between two zeros in a velocity-time curve is presented in equation (21), where $a$ is the time corresponding to the first zero, that is, the time at which the half cycle begins, while $b$ is the time corresponding to the second zero point, that is, the time at which the half cycle ends. The parameter (PI) defined in equation (22) is used for judgment. If the value of PI is greater than 0.5 , the velocity curve between the two zeros is a component of the velocity pulse in the seismic wave recording: 


$$
\begin{aligned}
\operatorname{FracEn}(1) & =\frac{\int_{a}^{b} v^{2}(t) \mathrm{d} t}{\int_{0}^{T} v^{2}(t) \mathrm{d} t}, \\
\mathrm{PI} & =\frac{1}{1+e^{7.64-27 \operatorname{FracEn}(1)}} .
\end{aligned}
$$

The velocity waveform of the ground motion used in this study is illustrated in Figure 20, in which the fling step ground motion is simulated by the half cycle of a harmonic pulse wave, and directivity pulse one is modeled by one cycle of a harmonic pulse. The pulseless ground motion is obtained by compressing and modulating the amplitude of the wave measured at the Songpan base station in the Wenchuan earthquake, which is $99 \mathrm{~km}$ away from the fault. The calculated PI values for the fling step and directivity pulse waveform are all greater than 0.9 , meeting the definition of pulse-like ground motion. The PI value of the modified wave from the Songpan station is less than 0.3, indicating that it is pulseless ground motion. For comparison, the generalized energy $E_{v}$ is used here, and the definition of which is as follows:

$$
E_{v}(t)=\int_{0}^{t} v^{2}(s) \mathrm{d} s, \quad(0 \leq s \leq t) .
$$

Let the generalized energy of the fling step, directivity pulse, and pulseless ground motion be equal. The variation in the generalized energy of the three ground motion types with time is illustrated in Figure 12.

3.4. Slope Failure Process and Mechanism. The spatial distribution of the failure points inside the slope under different ground motions is presented in Figure 21. The cumulative rupture process inside the slope over time is illustrated in Figure 22. It can be observed from the figure that the number of ruptures caused by the near-fault pulselike ground motion is substantially larger than that caused by the pulseless ground motion under the condition of the same excitation energy. The coupling between the nearfault pulse-like ground motion and the slope with a weak interlayer produces the largest number of ruptures. From the rupture type, shear failure accounts for a certain proportion of the failure inside the slope with a weak interlayer; however, for the homogeneous slope, the shear failure proportion is very small. From the spatial distribution of the rupture, for the slope with a weak interlayer, the shear failure is concentrated in the weak interlayer, while the tensile failure is concentrated in the rock mass above the interlayer. For the homogeneous slope, shear failure mainly occurs at the foot of the slope. From the cumulative process of rupture over time, it can be observed from Figures 20 and 21 that ruptures occur only at the steep part of the energy curve. For near-fault ground motion, the ruptures almost all appear in the time period affected by the pulse. The shear and tensile failure inside the slope with a weak interlayer occur synchronously, and the shear failure inside the homogeneous slope lags slightly behind the tensile failure.

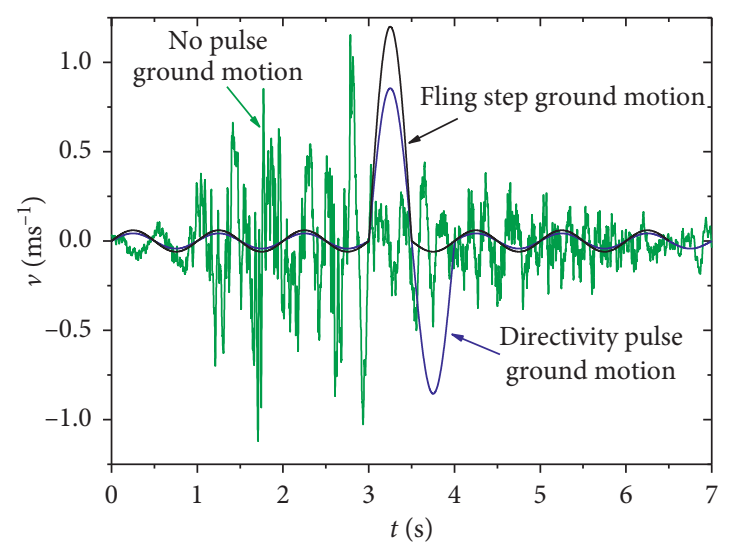

FIGURE 20: Velocity history.

Based on the above analysis, it can be concluded that the most serious damage occurs in the slope with a weak interlayer under near-fault pulse-like ground motions.

Different failure modes occur in the slope with a weak interlayer and homogeneous slope. For the slope with a weak interlayer, the shear failure zone mainly occurs in the weak interlayer, while the tensile failure zone appears in the rock mass above the interlayer. A sliding surface is formed when the tensile failure zone is connected to the shear failure zone. It can be observed from Figure 23(a) that the sliding mass is separated from the slope by the shear and tensile failure zones. For the homogeneous slope, the tensile failure appears at the upper part, while the shear failure mainly occurs at the foot of the slope. Only when the locking segment is cut off, can the sliding surface be penetrated, and the sliding mass can slide down. Compared to the homogeneous slope, the slope with a weak interlayer provides a shear opening for the sliding mass, and no locking segment exists in the slope. Therefore, the slope with a weak interlayer is more likely to be destroyed than the homogeneous slope.

In the aforementioned theoretical analysis, it was proven that the existence of the weak interlayer will lead to impacting and shearing effects in the interlayer owing to uncoordinated vibration. The velocity time history of the measuring points above and below the interlayer was recorded, as illustrated in Figure 24. It can be observed from the figure that the velocity difference between the rock masses at the upper and lower sides of the weak interlayer under the near-fault pulse-like ground motion is evident owing to the amplification effect and phase difference. The velocity difference for the homogeneous slope under the pulse-like ground motion is not large owing to the small phase difference (Figure 24(a)). The slope with a weak interlayer under pulseless ground motion (Figure 24(b)) exhibits a large phase difference and uncoordinated vibration, but the velocity difference is not as evident as that of the pulse-like ground motion owing to the small amplification effect. The time at which shear failure of the weak interlayer occurs is consistent with the time at which the large velocity difference appears. The large velocity difference induced by the coupling between the pulse-like ground motion and weak interlayer causes the weak interlayer to be subjected to 


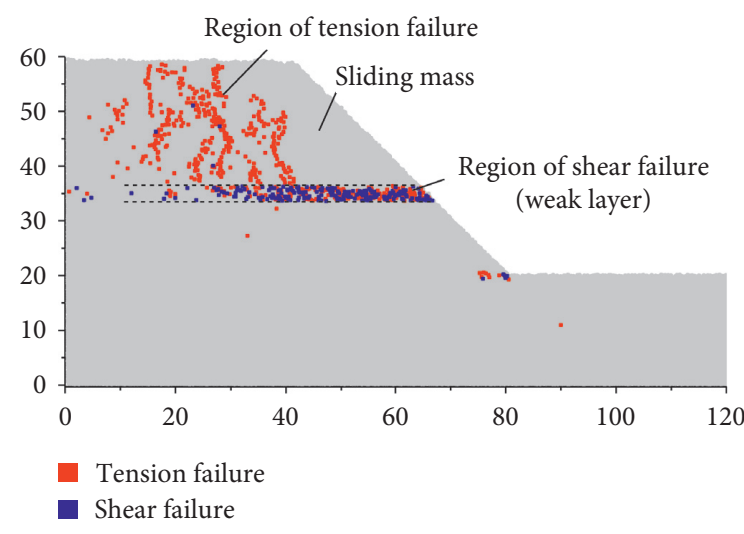

(a)

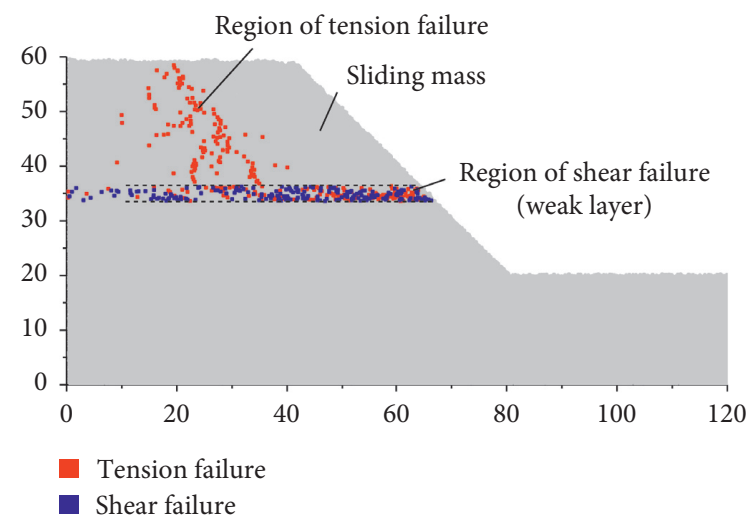

(c)

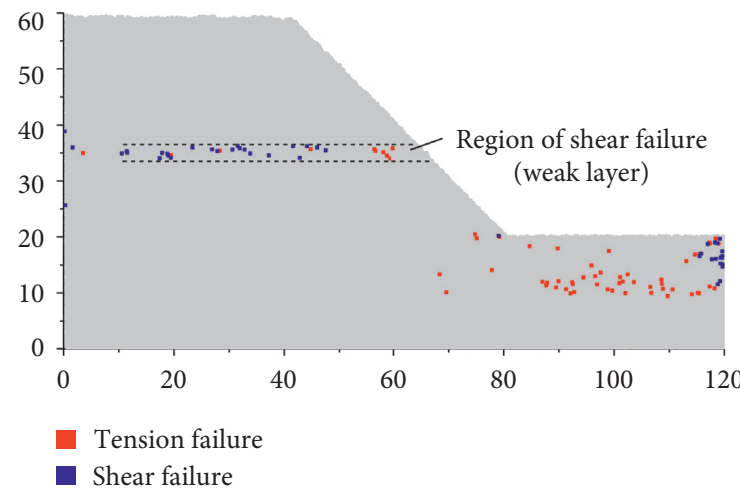

(e)

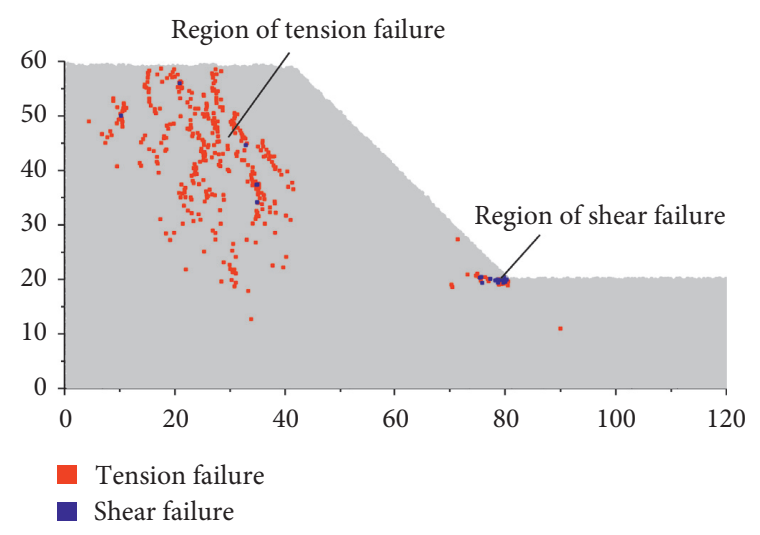

(b)

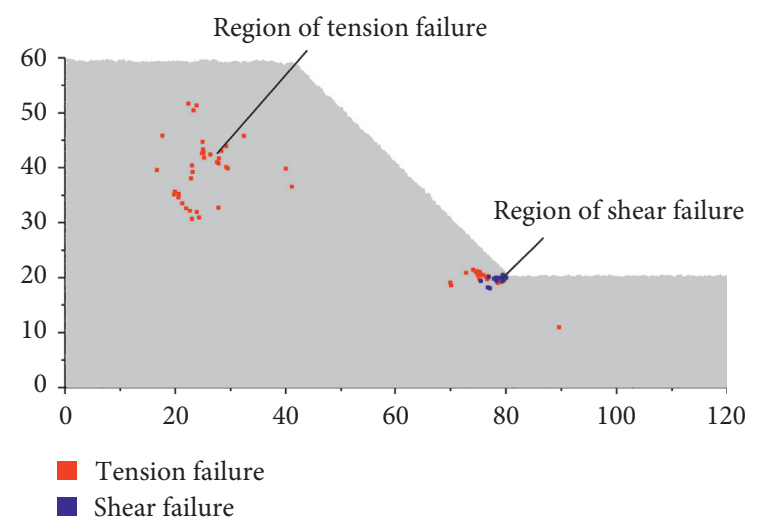

(d)

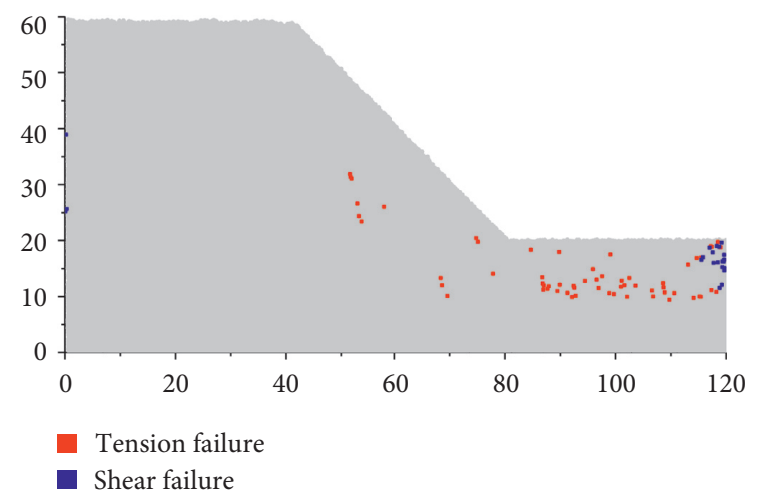

(f)

FigURE 21: Spatial distribution of failure points inside slopes under different ground motions. (a) Slope with a weak interlayer under fling step ground motion. (b) Homogeneous slope under fling step ground motion. (c) Slope with a weak interlayer under directivity pulse ground motion. (d) Homogeneous slope under directivity pulse ground motion. (e) Slope with a weak interlayer under pulseless ground motion. (f) Homogeneous slope under pulseless ground motion.

the impacting and shearing effects, which leads to impacting and shearing damage of the slope.

In the Wenchuan earthquake, the Daguangbao landslide was located near the fault $(4.8 \mathrm{~km})$, and the shear modulus and strength of the rock mass in the slip zone were smaller than those of the rock masses on both sides, so it was a slope with a weak interlayer. A scanning electron microscope was used to study the microscopic characteristics of the rock mass fragment in the sliding zone of the Daguangbao landslide by Huang et al. [29]. It was found that impacting failure of the rock mass occurred in the sliding zone (Figure 25). This verifies that the coupling between the near-fault pulse-like ground motion and weak interlayer will lead to impacting and shearing effects and cause the slope to be destroyed more easily.

In summary, the pulse-like near-fault ground motion coupled with a weak interlayer in the slope will induce impacting and shearing effects and a larger elevation amplification effect, causing the slope to reach failure more easily. The failure characteristics of a slope with a weak 


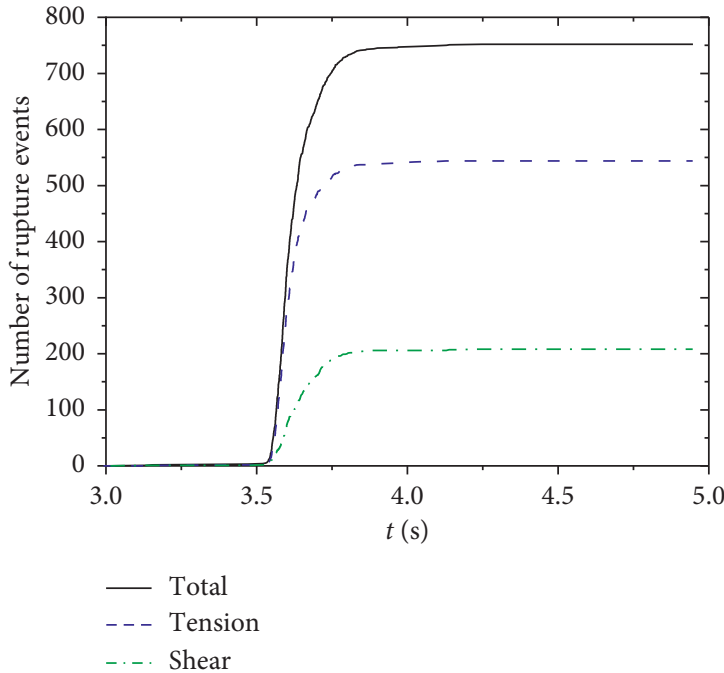

(a)

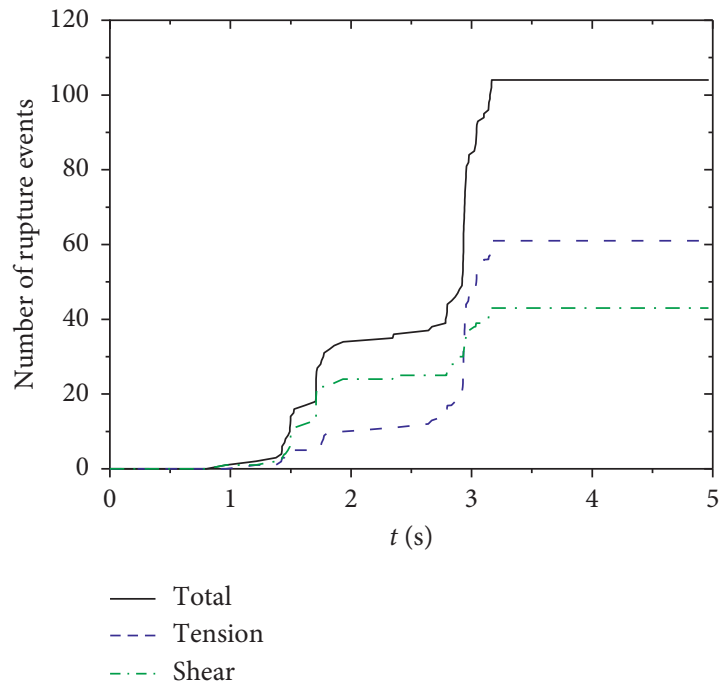

(c)

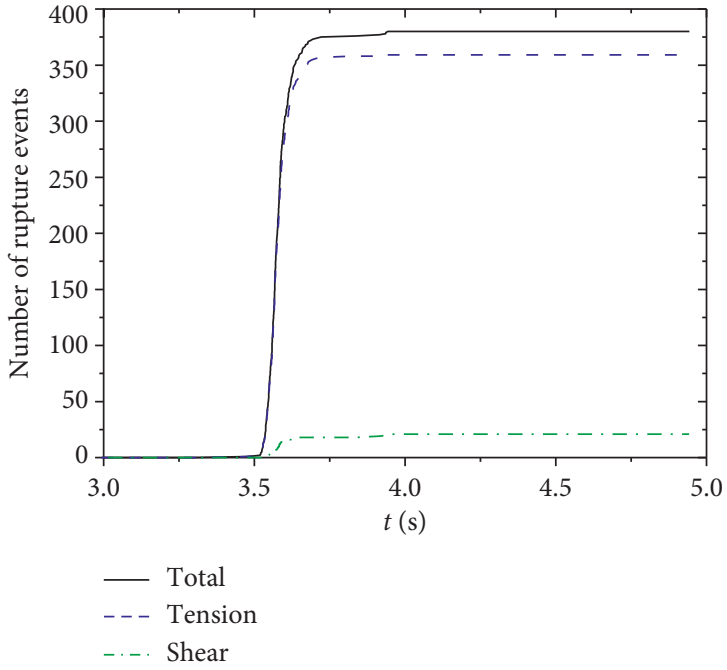

(b)

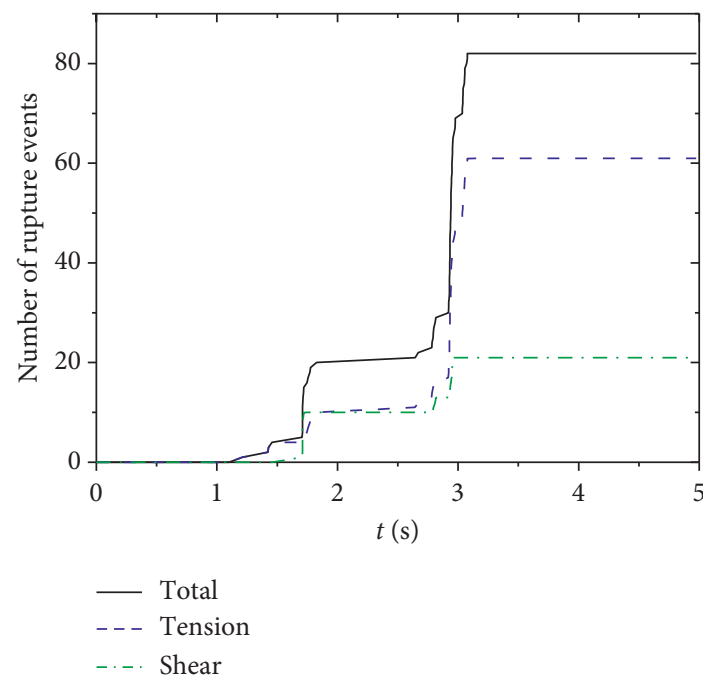

(d)

Figure 22: Cumulative failure process over time. (a) Slope with a weak interlayer under fling step ground motion. (b) Homogeneous slope under fling step ground motion. (c) Slope with a weak interlayer under pulseless ground motion. (d) Homogeneous slope under pulseless ground motion.

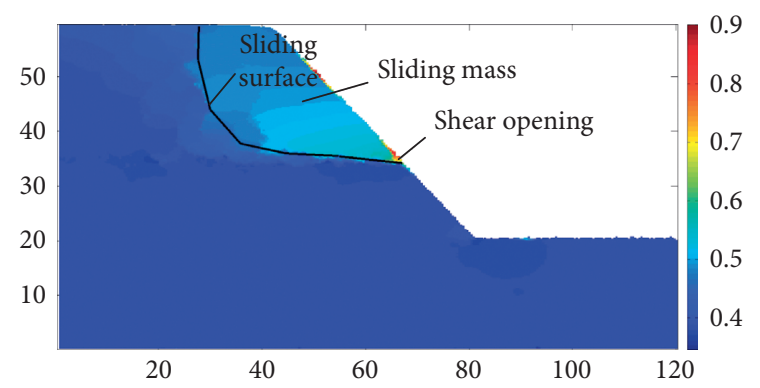

(a)

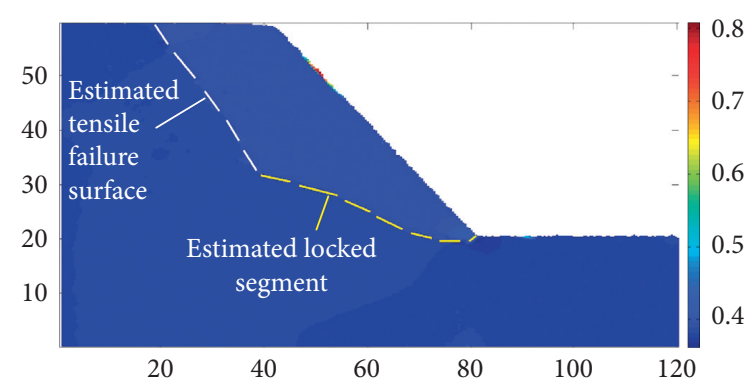

(b)

Figure 23: Contour of displacement. (a) Slope with a weak interlayer under fling step. (b) Homogeneous slope under fling step. 


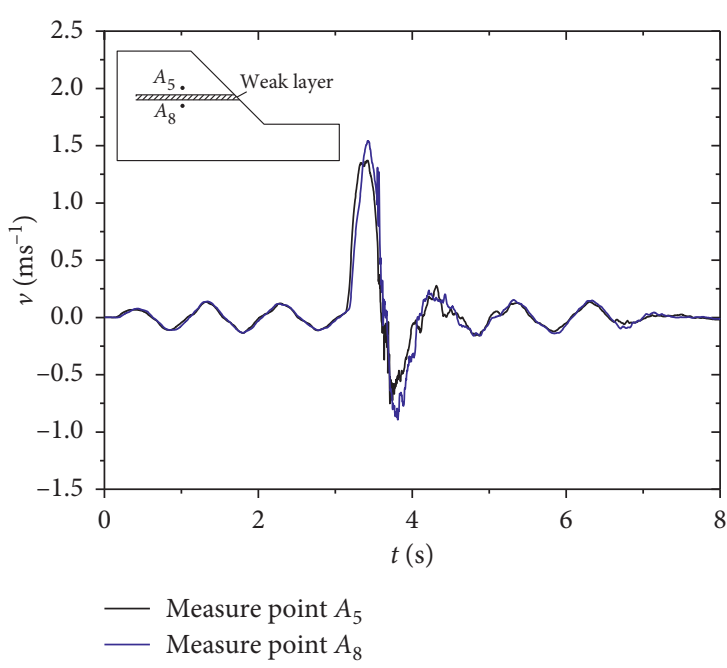

(a)

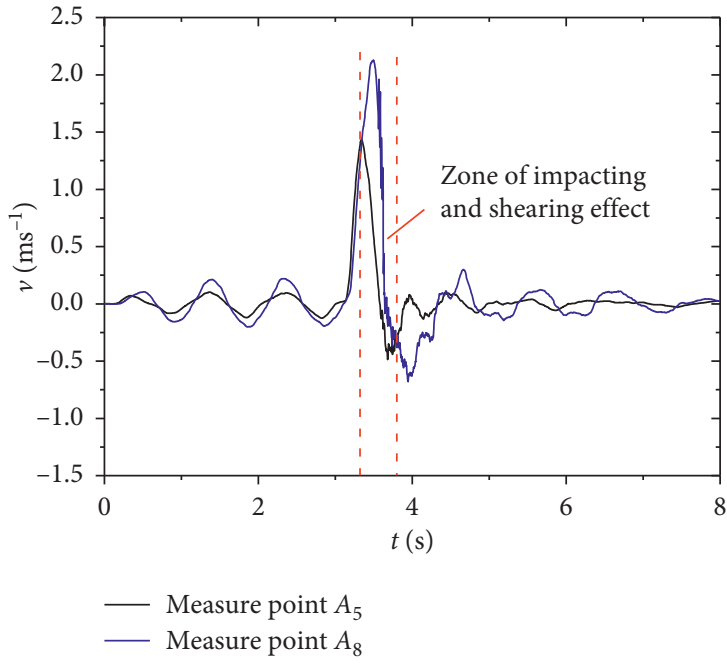

(c)

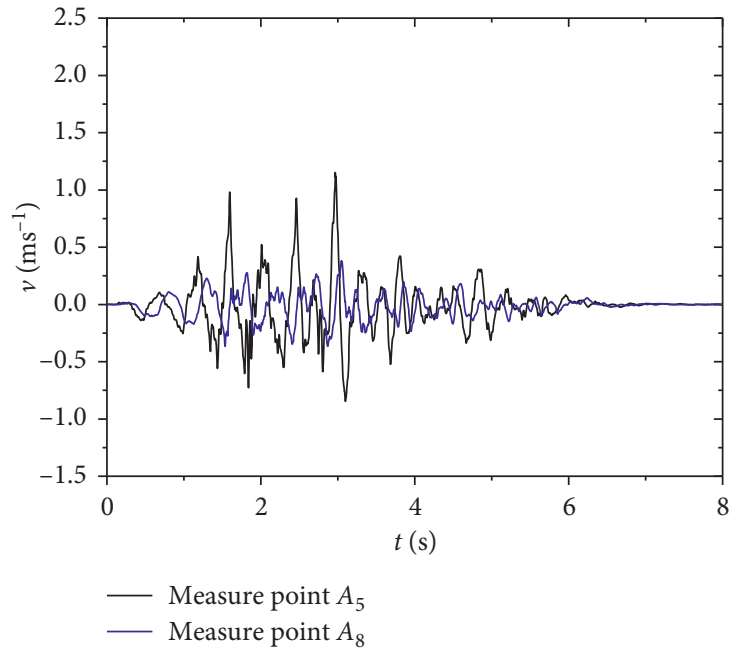

(b)

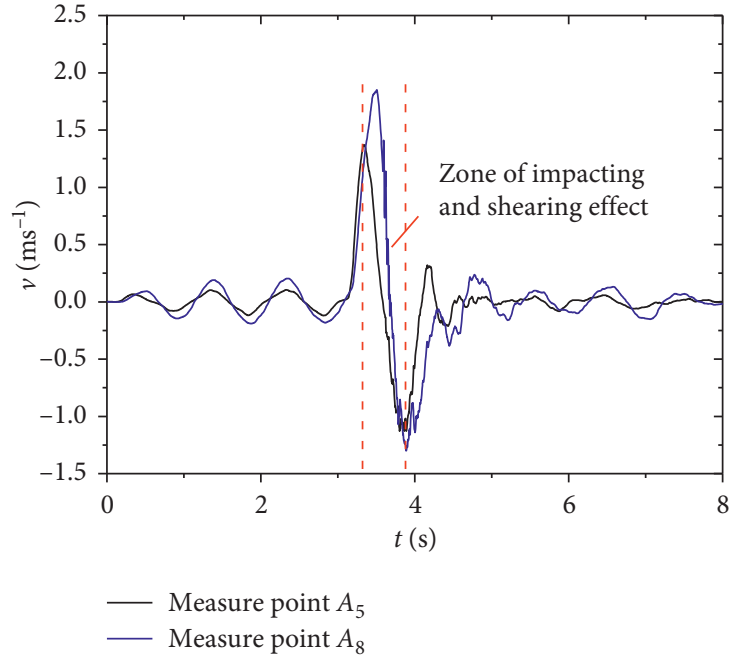

(d)

FigURE 24: Velocity time history of measuring points above and below the weak interlayer. (a) Homogeneous slope under fling step. (b) Slope with a weak interlayer under pulseless ground motion. (c) Slope with a weak interlayer under fling step. (d) Slope with a weak interlayer under directivity pulse.

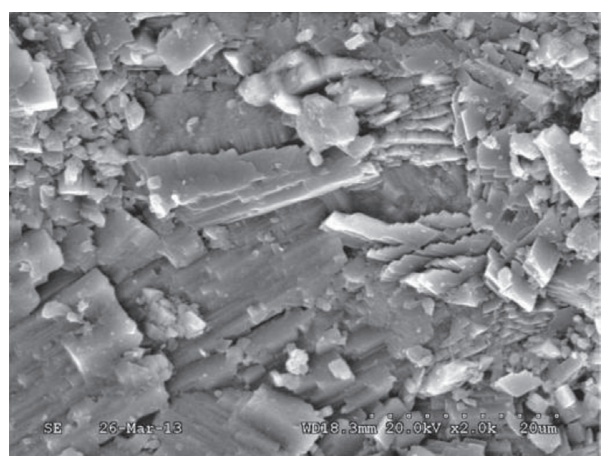

FIgURE 25: Microscopic image of impact failure of the rock mass in the slip zone of the Daguangbao landslide [29].

interlayer under pulse-like ground motion can be described as follows: the weak interlayer is destroyed by the impacting and shearing effects, and then, the tensile crack in the upper rock mass is induced by elevation amplification. Finally, the sliding mass slips out when the tension and shearing surface is penetrated. Therefore, in practical engineering, a slope 
with a weak interlayer near the fault should receive special attention, as it will be the most vulnerable slope. The shear strength of the weak interlayer and tension strength of the upper rock mass should be considered in the engineering design.

\section{Conclusions}

A mathematical model to investigate the dynamic response of a slope with a weak interlayer was established based on the shear beam theory. Moreover, a two-dimensional numerical model to study the failure process of a slope with a weak interlayer was established based on the DEM and PML boundary theory. Through the theoretical analysis and numerical simulation, the dynamic response and failure mode of the slope with a weak interlayer under the near-fault ground motion were studied. The following conclusions can be drawn:

(1) The weak interlayer in the slope will increase the first-order natural period of the slope evidently. A smaller shear modulus or larger thickness of the interlayer results in a longer natural period of the slope. The weak interlayer will cause the natural period of the slope to become closer to the period of pulse-like ground motion, leading to greater damage. The influences of the thickness and shear modulus of the interlayer on the dynamic response of the slope are achieved by changing the natural period of the slope.

(2) The variation in the amplification effect with the elevation is mainly related to the ratio of the seismic period to the natural period of the slope. At low frequencies (below or close to the first-order natural frequency of the slope), the dynamic response of the slope with or without a weak interlayer is close to the first-order vibration mode of the slope, and the amplification effect of the slope with a weak interlayer is substantially larger than that of the homogeneous slope. At high frequencies (far greater than the first-order natural frequency of the slope), the dynamic response of the slope with or without a weak interlayer is close to the second-order vibration mode of the slope, and the amplification effect of the slope with a weak interlayer is not significantly different from that of the homogeneous slope. Moreover, the interlayer has a vibration isolation effect on the high-frequency ground motion, which means that the amplification effect at the rock mass above the interlayer is smaller.

(3) Under the action of horizontal ground motion, the weak interlayer will be subjected to impacting and shearing action. Under near-fault pulse-like ground motion, the impacting and shearing effects of the weak interlayer are substantially greater than those of pulseless ground motion.

(4) The failure characteristics of the slope with a weak interlayer under pulse-like ground motion can be expressed as follows: the weak interlayer is destroyed by the impacting and shearing effects, following which a tension crack in the rock mass above the interlayer is induced by the elevation amplification. Finally, the sliding mass slips out when the tension and shearing surface is penetrated.

In practical engineering, a slope with a weak interlayer near the fault will be the most vulnerable slope. The shear strength of the weak interlayer and tension strength of the rock mass above the interlayer should be considered in the engineering design.

\section{Data Availability}

The data used to support the findings of this study are available from the corresponding author upon request.

\section{Conflicts of Interest}

The authors declare that they have no conflicts of interest.

\section{Acknowledgments}

This study was supported by the National Natural Science Foundation of China (no. 10902112), Fundamental Research Funds for the Central Universities (2682017QY02), Key R\&D Projects in Sichuan Province (2021YFS0323 and 2020YFG0123), Applied Basic Research of Science and Technology Plan projects in Sichuan Province (2021YJ0039), and Sichuan International Cooperation Project (2020YFH0017).

\section{References}

[1] R. Huang and W. Li, "Development and distribution of geohazards triggered by the 5.12 wenchuan earthquake in China," Science in China Series E: Technological Sciences, vol. 52, no. 4, pp. 810-819, 2009.

[2] Q. Xu, X. J. Pei, R. Q. Huang et al., Large-Scale Landslides Induced by Wenchuan Earthquake, Science Press, Beijing, China, 2009.

[3] B. Zhao, F. Taucer, and T. Rossetto, "Field investigation on the performance of building structures during the 12 May 2008 Wenchuan earthquake in China," Engineering Structures, vol. 31, no. 8, pp. 1707-1723, 2009.

[4] Q. Xu, S. Zhang, and W. Li, "Spatial distribution of large-scale landslides induced by the 5.12 Wenchuan earthquake," Journal of Mountain Science, vol. 8, no. 2, pp. 246-260, 2011.

[5] M. D. Trifunac, "The role of strong motion rotations in the response of structures near earthquake faults," Soil Dynamics and Earthquake Engineering, vol. 29, no. 2, pp. 382-393, 2009.

[6] G. P. Mavroeidis and A. S. Papageorgiou, "A mathematical representation of near-fault ground motions," Bulletin of the Seismological Society of America, vol. 93, no. 3, pp. 1099-1131, 2003.

[7] L. S. Burks and J. W. Baker, "A predictive model for fling-step in near-fault ground motions based on recordings and simulations," Soil Dynamics and Earthquake Engineering, vol. 80, pp. 119-126, 2016.

[8] J. D. Bray and A. Rodriguez-Marek, "Characterization of forward-directivity ground motions in the near-fault region," 
Soil Dynamics and Earthquake Engineering, vol. 24, no. 11, pp. 815-828, 2004.

[9] Z. Wen, J. Xie, M. Gao, Y. Hu, and K. T. Chau, "Near-source strong ground motion characteristics of the 2008 Wenchuan earthquake," Bulletin of the Seismological Society of America, vol. 100, no. 5, pp. 2425-2439, 2010.

[10] Q. Han, X. Du, J. Liu, Z. Li, L. Li, and J. Zhao, "Seismic damage of highway bridges during the 2008 Wenchuan earthquake," Earthquake Engineering and Engineering Vibration, vol. 8, no. 2, pp. 263-273, 2009.

[11] Z.-L. Chen, X. Hu, and Q. Xu, "Experimental study of motion characteristics of rock slopes with weak intercalation under seismic excitation," Journal of Mountain Science, vol. 13, no. 3, pp. 546-556, 2016.

[12] B. Yang, Y. Luo, D. Jeng, and J. Feng, "Effects of moisture content on the dynamic response and failure mode of unsaturated soil slope subjected to seismic load," Bulletin of Seismological Society of America, vol. 109, no. 2, pp. 489-504, 2019.

[13] B. Yang, F. Gao, and D. Jeng, "Failure mode and dynamic response of a double-sided slope with high water content of soil," Journal of Mountain Science, vol. 15, no. 4, pp. 859-870, 2018.

[14] R. Huang, "Modelling of the effects of properties of a buried weak layer on seismic waves," Journal of Engineering Geology, vol. 11, no. 3, pp. 312-317, 2003.

[15] L. P. Liu, S. J. Yang, and L. I. Ying-Min, "Influence of soft soil layer on dynamic characteristic of the slope," Journal of Chongqing University, vol. 30, no. 5, pp. 31-34, 2007.

[16] B. Xu, Q. Qian, C. Yan et al., "Stability and strengthening analyses of slope rock mass containing multi-weak interlayers," Chinese Journal of Rock Mechanics and Engineering, vol. 28, no. s2, pp. 3959-3964, 2009.

[17] J. Deng, H. Kameya, Y. Miyashita, J. Kuwano, R. Kuwano, and J. Koseki, "Study on a failed dip slope with a thin sandy layer in 2004 Niigata-ken Chuetsu earthquake," Engineering Geology, vol. 123, no. 4, pp. 302-314, 2011.

[18] M. Huang, H. Wang, D. Sheng, and Y. Liu, "Rotational-translational mechanism for the upper bound stability analysis of slopes with weak interlayer," Computers and Geotechnics, vol. 53, no. 13, pp. 133-141, 2013.

[19] G. Fan, J. Zhang, J. Wu, and K. Yan, "Dynamic response and dynamic failure mode of a weak intercalated rock slope using a shaking table," Rock Mechanics \& Rock Engineering, vol. 49, no. 8, pp. 1-14, 2016.

[20] B. Yang, Z. Zhou, and L. Zhou, "Experimental study on instability characteristic and bearing capacity of slope with bedrock under the action of rainfall," Journal of Southwest Jiaotong University, 2020, in Chinese.

[21] S. Cui, X. Pei, and R. Huang, "Effects of geological and tectonic characteristics on the earthquake-triggered Daguangbao landslide, China," Landslides, vol. 15, no. 8, pp. 1-19, 2017.

[22] X. P. Zhou and H. Cheng, "Stability analysis of three-dimensional seismic landslides using the rigorous limit equilibrium method," Engineering Geology, vol. 174, no. 8, pp. 87-102, 2014.

[23] Z. Chang, X. Sun, C. Zhai, J. X. Zhao, and L. Xie, “An improved energy-based approach for selecting pulse-like ground motions," Earthquake Engineering \& Structural Dynamics, vol. 45 , no. 14, pp. 2405-2411, 2016.

[24] J. D. Bray, "Simplified seismic slope displacement procedures," Geotechnical, Geological and Earthquake Engineering, pp. 327-353, 2007.
[25] P. A. Cundall and O. D. L. Strack, "A discrete numerical model for granular assemblies," Geotechnique, vol. 29, no. 30, pp. 331-336, 2008.

[26] J. He, X. Li, S. Li, Y. Yin, and H. Qian, "Study of seismic response of colluvium accumulation slope by particle flow code," Granular Matter, vol. 12, no. 5, pp. 483-490, 2010.

[27] G. D. Zhang, "Effect of different boundary conditions and seismic waves on seismic response of a slope," Journal of Vibration \& Shock, vol. 30, no. 1, pp. 102-105, 2011.

[28] S. Mukhopadhyay and V. K. Gupta, "Directivity pulses in near-fault ground motions-I: identification, extraction and modeling," Soil Dynamics and Earthquake Engineering, vol. 50, no. 6, pp. 1-15, 2013.

[29] R. Huang, X. Pei, and S. Cui, "Cataclastic characteristics and formation mechanism of rock mass in sliding zone of daguangbao landslide," Chinese Journal of Rock Mechanics \& Engineering, vol. 35, no. 1, pp. 1-15, 2016. 